\title{
Ultra-low fertility in East Asia: Confucianism and its discontents
}

\author{
Yen-hsin Alice Cheng ${ }^{1, *}$
}

\begin{abstract}
This study reviews the institutional factors that have influenced the fertility and family trends in five East Asian societies that experienced a precipitous transition to very low fertility: China, Japan, Hong Kong, South Korea and Taiwan. The paper begins by outlining the unique family formation patterns of these societies and the existing explanations for their observed ultra-low fertility levels. In particular, it highlights the role of Confucian culture, which emphasises patriarchal values and credentialism, in shaping the current state of low fertility in East Asia. For example, the ways in which Confucianism affects women's roles at home, the effectiveness of pronatalist policies and the burden of human capital investments among parents are discussed. With these contextual factors and the current very low fertility rates as a backdrop, this study also examines attitudinal changes in marriage and family values that have taken place in these societies after the new millennium. These changes could further erode the traditional family and influence family formation trends in the future. The article concludes by discussing recent policy responses and the possible future of fertility in East Asia.
\end{abstract}

Keywords: fertility transition; ultra-low fertility; East Asia; Confucianism; patriarchy; credentialism; value changes; pronatalist policies

\section{Introduction}

Health Minister Hakuo Yanagisawa, 71, in January publicly described women as 'baby-making machines' and suggested Japan had a birthrate problem because women were failing in their duty to produce children. In November, Hakubun Shimomura, 52, one of Prime Minister Shinzo Abe's top aides, said the country could easily address a national shortage

\footnotetext{
${ }^{1}$ Institute of Sociology, Academia Sinica, Taipei, Taiwan

${ }^{*}$ Correspondence to: Yen-hsin Alice Cheng, aliceyh@gate.sinica.edu.tw
} 
of public daycare if women would simply 'stay at home and raise their children'.

Washington Post, March 2007

In East Asia, matrimony and childbearing have been seen for centuries as paramount life events of unquestionable moral significance and status for young adults. However, by 2018, three East Asian advanced economies (i.e. Hong Kong, Taiwan and South Korea) have all experienced period total fertility rates (TFR) below one child per woman, a level that is almost unprecedented in any Western lowfertility society. ${ }^{1}$ While tempo effects play a crucial role in causing such low rates, cohort total fertility rates (CTFR) have also declined from at least two children for the early 1950 s cohorts to $1.2-1.8$ children for those born in 1970. Such dramatic changes have led to concerns being raised and some fingers being pointed in this region, which has long been characterised by patriarchy and misogyny. When very low fertility rates first hit this region after the 1990s, accusations that young people are selfish and materialistic began to emerge. It is not uncommon to hear politicians making comments about how young women are deviating from their traditional childbearing and homemaker roles and duties. Derogatory terms such as "leftover women" and "loser dogs" have also been coined to describe unmarried, childless women above age 30. Indeed, the city mayor of Taipei in Taiwan, Wen-Je Ko, once blamed women for posing national security concerns by not marrying and having children, and only changed his statement to include men after single women and feminist groups expressed irritation (Gerber 2015). Similar comments about a single Korean female professor nominated for a government position also sparked anger in 2019 (McCurry 2019). This kind of scapegoat narrative lies at the heart of the Confucian patriarchal culture that is shared across all East Asian societies (GietelBasten 2019).

Meanwhile, East Asia is also a region in which female empowerment through education and employment has progressed tremendously over the past few decades. It has, however, become clear that the relatively rigid patriarchal cultural and family systems of East Asia are maladapted to women's rising status and economic independence. The traditional social order of male and elder dominance at home has become increasingly incompatible with women's professional pursuits and their expectations of an ideal marriage. This mismatch inevitably lowers women's motivations to get married and to bear children, as doing so tends to entail obligations that hinder women's personal aspirations, and that confine them within the domestic realm under the traditional Confucian ideology of ideal wifehood and motherhood. In addition, traditional Confucian values place heavy emphasis on academic attainment, which has its roots in the civil service exam system in ancient China. These ingrained values are reflected in a shared strong valuation of academic

\footnotetext{
A very low TFR of 0.77 was once observed in eastern Germany (the former GDR) during 1993-94, shortly after the unification of Germany.
} 
pursuits, which translates into the prevailing credentialism found in the region. This increases the costs of raising children and heightens the quality-quantity anxiety among (would-be) parents.

While past research has provided explanations for why fertility rates declined to very low levels so rapidly in East Asia, most of these studies focused on social and structural changes. Very few studies have attempted to look at the overarching cultural ideology that has shaped the unique fertility patterns in East Asia. This paper will begin by offering an overview of the social and demographic profiles of five East Asian societies ${ }^{2}$ that experienced precipitous transitions to very low fertility. We will then review the paths to ultra-low fertility levels and the unique features of these societies, followed by the commonly discussed causes that give rise to such phenomena. In particular, this study highlights the role of Confucian culture, which emphasises patriarchal values and credentialism, in shaping the current low rates of family formation in the region; and how it influences women's roles at home, the effectiveness of pro-natalist policies and the burden of human capital investments among parents. With these contextual factors and current very low fertility rates as a backdrop, we also examine attitudinal changes in marriage and family values that have taken place in these societies after the new millennium. These changes could further erode the traditional family and influence family formation trends in the future. The article concludes by discussing recent policy responses and the possible future of fertility in East Asia.

\section{The region of East Asia}

Slightly more than one-fifth (roughly 1.6 billion) of the world's population live in East Asia, and the region is home to some of the fastest growing economies of the past half century. However, the socio-historical backgrounds of these societies vary. China has been a socialist state since the mid-20th century and underwent economic reforms in the late 1970s. Hong Kong was a colony of the United Kingdom until 1997 and has remained a global financial centre since it was returned to China. While industrialisation started as early as in the late 19th century in Japan, it took off much later in Taiwan and South Korea (abbreviated as Korea hereafter), and did not affect their demographic development until the latter half of the 20th century. These socio-historical factors have created different trajectories of economic development and paces of fertility decline across these societies. For instance, the timing of the emergence of below-replacement fertility across the region ranges from the

2 The societies included in this study are China, Hong Kong, Japan, South Korea and Taiwan. Mongolia and North Korea will not be discussed, mainly because of their near-replacement-level fertility rates and data availability issues. While Singapore has undergone cultural, economic and demographic developments similar to those of its East Asian neighbors, geographically it is located in Southeast Asia, and will not be discussed here. 
Table 1:

Socio-economic and demographic profiles of five East Asian societies

\begin{tabular}{lccccc}
\hline & China & $\begin{array}{c}\text { Hong } \\
\text { Kong }\end{array}$ & Japan & $\begin{array}{c}\text { South } \\
\text { Korea }\end{array}$ & Taiwan \\
\hline Population (in millions) & 1,400 & 7.4 & 127 & 51.5 & 23.5 \\
GDP per capita (nominal) & $\$ 9,610$ & $\$ 48,520$ & $\$ 39,310$ & $\$ 31,350$ & $\$ 24,970$ \\
$\mathrm{HDI}^{2} 2018$ & 0.752 & 0.933 & 0.909 & 0.903 & 0.907 \\
$\mathrm{TFR}^{3} 2018$ & $1.64^{6}$ & 1.07 & 1.42 & 0.98 & 1.06 \\
$\mathrm{CTFR}^{2}$ cohort 1970 at age 40) & 1.70 & 1.15 & 1.43 & 1.75 & 1.70 \\
$\%$ childless for cohort 19705 & n.a. & $35 \%$ & $27 \%$ & $10 \%$ & $16 \%$ \\
\hline
\end{tabular}

Note: ${ }^{1}$ Based on 2018 IMF data; ${ }^{2}$ HDI refers to Human Development Index; ${ }^{3}$ TFR refers to the period total fertility rate; ${ }^{4}$ data compiled from the Human Fertility Database, Frejka (2017) and Myrskylä et al. $(2013) ;{ }^{5}$ the childlessness statistics come from the Human Fertility Database and the 2018 Hong Kong Monthly Digest of Statistics (Census and Statistics Department 2018); ${ }^{6}$ the TFR reported by the National and Local Health and Family Planning Commissions is 1.6 (Leng 2017), but Guo et al. (2019) reported that the TFR is 1.05 based on the $20151 \%$ micro-census in China.

mid-1950s in Japan to the early 1990s in China. By the latter half of the 2000s, the countries of East Asia were experiencing some of the lowest fertility levels ever recorded in the world (i.e. the TFR reached a low of 0.9 in 2003 in Hong Kong and in 2010 in Taiwan).

The socio-economic and demographic profiles of East Asian societies differ markedly (Table 1). Hong Kong has the smallest population, but the highest income levels and human development score in the region. In contrast, compared to its neighbours, China has the largest population and a higher period total fertility rate (at least according to some sources), but lower income levels and a lower human development score. Taiwan and South Korea have more similar profiles in terms of income levels, period total fertility rates and human development indices, whereas Japan has higher income levels and period fertility rates than these two countries. The gap between the TFR and the cohort fertility rates (CTFR) observed at age 40 for women born in 1970 suggests that in Korea and Taiwan, there have been strong tempo effects as well as declines in fertility quantum due to increased rates of lifelong singlehood. In contrast, the tempo effect in China is less visible, and the narrow difference between the TFR and the CTFR in Hong Kong reflects a convergence of both period and cohort fertility to extreme low levels. In addition, the share of childless women in the 1970 cohort reveals how variations in the levels of completed fertility rates can be attributed to diverging rates of childlessness. The speed of increases in the percentages of childless women has been remarkable: from about $11 \%$ to $28 \%$ for the cohorts born between the early 1950s and 1970s in Japan; and from about $9 \%$ to $16 \%$ for those born in the early 1960s and 1970s in Taiwan. These contextual differences set the backdrop against which different trajectories of the fertility transition came into being in contemporary East Asia. 
While the remarkable economic growth in the region since the 1970s is often cited as the cause of the rapid decline in fertility to very low levels, the deeprooted Confucian culture in East Asia is another crucial factor. This cultural system is characterised by a hierarchical and patriarchal social order in which men have dominance over women, the elderly have higher status than the young, and rulers have more power than their subjects. Confucianism not only governs family life, it puts great emphasis on educational credentials earned through the state examination system. It also places a woman (wife) in a subordinate position relative to her husband. These hierarchies were historically facilitated by low levels of education and high levels of illiteracy, and by early marriage for women, which was common well into the 20th century. The remnants of these practices have hampered the progress of gender equality in recent decades. When placed within a collectivist family system, persistent gender inequalities make childbearing and childrearing a heavy burden for young couples in societies with rising living standards and increasingly competitive market economies. ${ }^{3}$

\section{East Asian fertility transition}

\subsection{Rapid fertility decline within four decades}

While in the Western developed world, period fertility rates have been at their historically lowest levels since the 1970s, very low fertility did not emerge in East Asia until the 1990s. Unlike the patterns observed in most regions in Europe, in which a fertility reversal often took place after a historical low point was reached, the majority of East Asian societies have reported TFRs below 1.5 for two decades or longer. While the CTFR rarely dropped below 1.5 children in the Western developed countries (except in Southern Europe), the forecasted CTFR for the late 1970s cohorts will likely dip below 1.5 children for Taiwan, Japan and Korea (Myrskylä et al. 2013) and will certainly be below this level in Hong Kong. The speed and the scope of the fertility decline in East Asia are remarkable, particularly given the region's collectivist culture with strong family traditions. By the end of the 2010s, East Asia had become a region with persistent ultra-low fertility that was reporting some world record-breaking period rates: both Hong Kong and Taiwan reached the

\footnotetext{
3 Even though Singapore, with a population of 5.6 million, is not included in this paper, it is also a high-income Confucian country with a GDP per capita (nominal) of 64,580 U.S. Dollars and a high HDI of 0.935 in 2018. Low period fertility rates below 1.5 children were first observed for a few years in the late 1980s and again since the late 1990s until today. In 2018, the period TFR was only 1.14 children. The cohort TFR for the early 1960s cohorts is 1.82 and will likely drop just below 1.5 for the early 1970 s cohorts (Chuan 2010). Nearly $25 \%$ of women aged 40-44 remained childless in the early 2010s (United Nations 2014).
} 
Figure 1:

Period total fertility rates in East Asia, 1960-2016

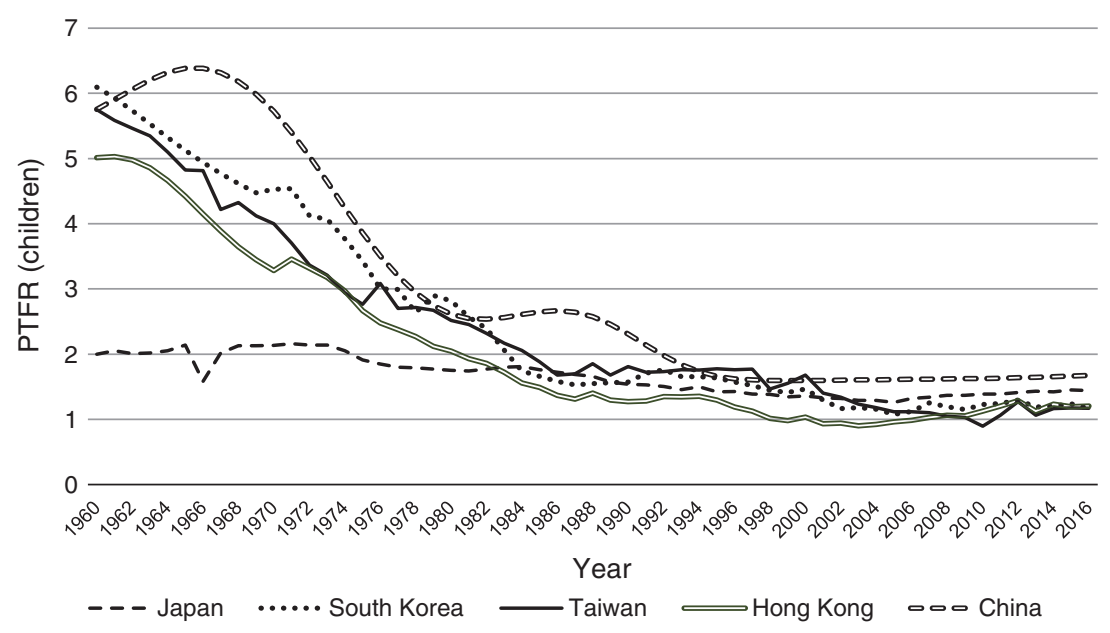

Source: Figures for Japan, South Korea and Hong Kong come from World Bank Database (https://data.worldbank. org/indicator/SP.DYN.TFRT.IN/). Figures for China come from the United Nations 2019 World Population Prospects. Figures for Taiwan come from the Population Statistics Database, Ministry of the Interior, Taiwan (https://www.ris. gov.tw/app/portal/346).

historically low period fertility rate of 0.9 in 2003 and 2010, respectively; and in 2019, South Korea experienced an extremely low period total fertility rate of 0.92 .

These five societies have undergone their fertility transitions at different speeds, and their total fertility rates have been substantially suppressed by tempo effects due to delayed childbearing. As Figure 1 shows, Japan experienced the earliest fertility transition from five children per woman in the pre-war era to a belowreplacement level in 1957 (Tsuya 2017). The fertility transition happened much later in Hong Kong than in Japan, with Taiwan and South Korea experiencing very similar trajectories (Basten 2015). China was the last country in the region to reach below-replacement fertility, as it did not achieve that level until the early 1990s. During these periods of rapid fertility change, fertility quantum initially declined due to decreasing marital fertility rates. Tempo effects caused by the delayed timing of marriage (and thus, of childbearing) also suppressed period TFR. As the latter effects persisted for some time, parts of the "tempo" impact became permanent "quantum" losses due to rising levels of lifelong singlehood (and thus, of childlessness) in this region. Such patterns have been observed in Taiwan, Japan, Hong Kong, and South Korea (Yoo and Sobotka 2018; Frejka and Ross 2001; Jones 2007; Frejka et al. 2010). 
Figure 2:

GDP per capita in five East Asian societies (U.S. dollars at 2010 price)

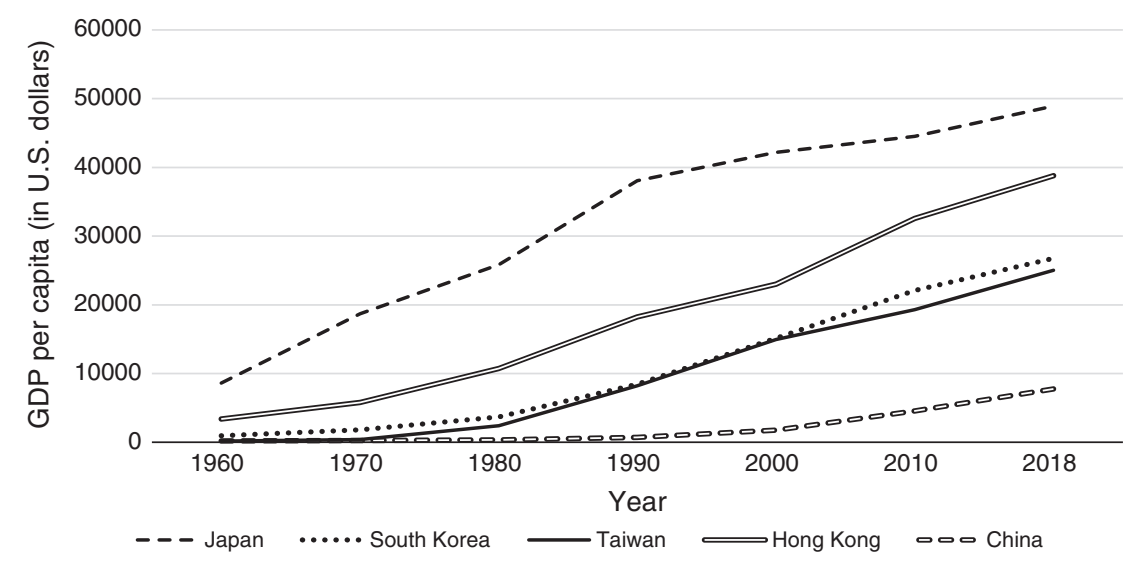

Source: Population Statistics Database of Taiwan (https://eng.stat.gov.tw/point.asp?index=1); World Development Indicators from the World Bank (https://data.worldbank.org/indicator/NY.GDP.PCAP.KD).

These rapid fertility transitions occurred during times of tremendous economic growth and female empowerment in the region. All societies in East Asia experienced impressive growth in GDP per capita during the post-war years, albeit at different paces. Figure 2 shows that Japan, as the earliest industrialised country in the region, achieved the highest GDP throughout the entire observation period, followed by Hong Kong. Taiwan and Korea have experienced very similar trajectories and levels of GDP growth, while China's level of economic development is still much lower than that of its neighbours, even though its growth rates over the past two to three decades have been remarkable.

Economic growth fuelled by industrialisation and subsequent labour demands have prompted governments in most of these societies to expand educational opportunities or to lengthen the duration of compulsory education. Figure 3 presents the trends in the shares of men and women aged 25-29 with tertiary education from 1970 to 2010 in these five societies. Japan began investing heavily in human capital from the 1970s to the 1990s. Thus, Japan was a forerunner in the trend towards investments in higher education in the region, largely due to the Meiji Restoration and its early initiation of industrialisation starting in the late 19th century. The trends in Korea and Taiwan converged to that in Japan in the mid-2000s, with more than half of the population aged 25-29 completing tertiary education in these three countries by 2010 . The corresponding share is a bit lower in Hong Kong, at $45 \%$; while China has the lowest share of tertiary education graduates, at less than $10 \%$.

This rapid educational expansion also contributed to more women entering the labour force. The trajectories of female labour force participation (FLFP) patterns 
Figure 3:

Percentage of population aged 25-29 with tertiary education

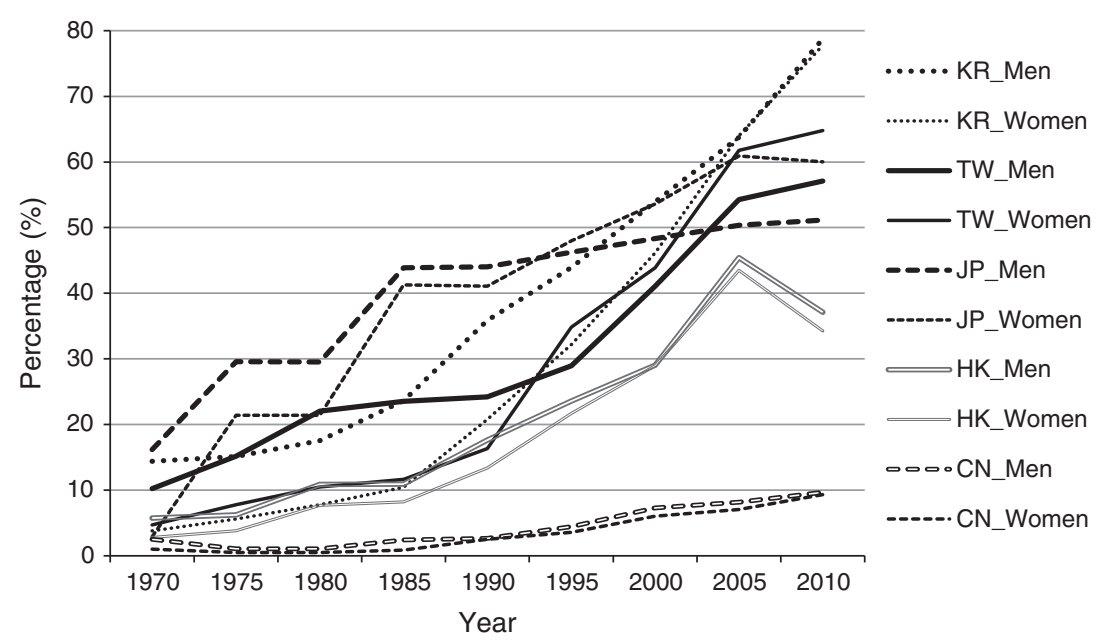

Source: Barro and Lee (2018).

in Japan and Taiwan have exhibited impressive levels of growth across all ages since 1990 (Figure 4). The patterns in Korea are slightly different: there has been a dramatic rise in FLFP among women in their late twenties, but FLFP has stagnated somewhat (or even decreased) for women in their late thirties and early forties. Longterm time series data for FLFP by age are not available for Hong Kong and China, although the existing statistics indicate that female labour force participation rates in Hong Kong increased from 47\% in 1990 to $54 \%$ in 2018, and the comparable rates for China declined from $73 \%$ to $61 \%$ over the same period (The Global Economy 2019; International Labor Organization 2019).

As the years spent in education and levels of labour force participation have risen among women at prime reproductive ages, marriages have increasingly been delayed or even foregone. In all five societies, marriages have been postponed to much later ages since 1970, although the pace of the rise in the mean age at first marriage has been less dramatic in China (Figure 5). Along with delayed matrimony, levels of lifelong singlehood have increased rapidly in all societies in the region except China (Figure 6). Overall, the patterns observed in China up to 2010 indicated that the country still had a relatively early and universal marriage regime. However, delayed marriage and rising levels of singlehood have become more prevalent in China during the last decade. According to the National Bureau of Statistics in China, the number of registered marriages has declined rapidly, from 13 million in 2014 to 10.6 million in 2017; while the mean age at first marriage among women has risen to 25.7 years. Past research also indicates that there are notable 


\section{Figure 4:}

Female labor force participation rates by age and year since 1990
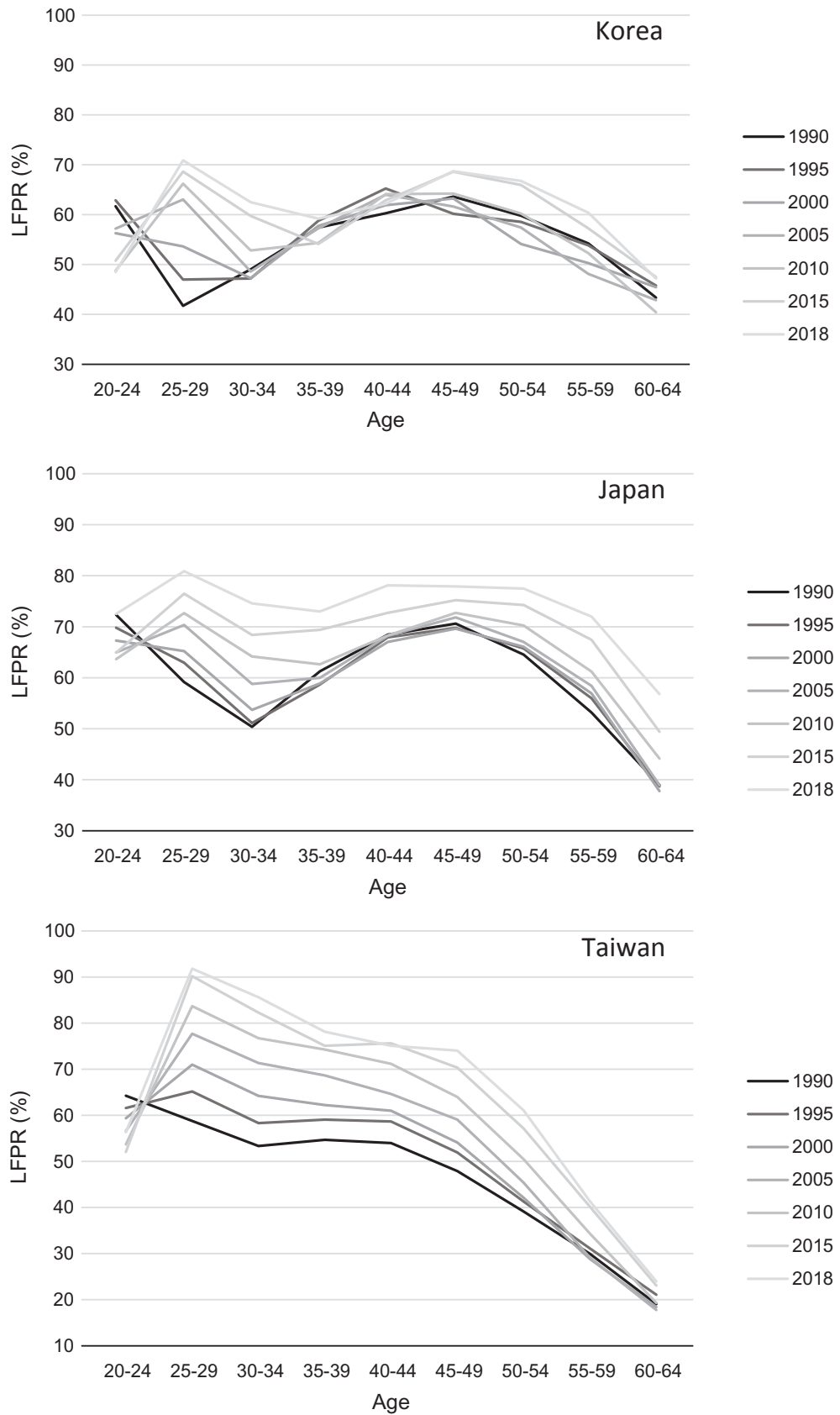

Source: OECD Statistics Database and National Statistics Database of Taiwan. 
Figure 5:

Mean age at first marriage among women in five East Asian societies, 1970-2015

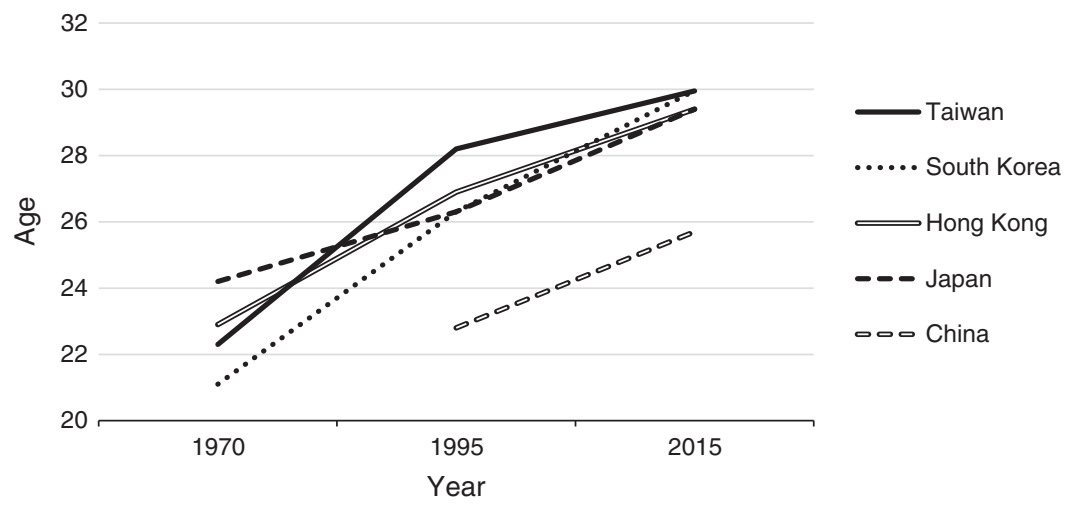

Source: Taiwan: Population Statistics Database (https://www.ris.gov.tw/app/portal/346); South Korea: KOSISKorean Statistical Information Services; Japan: e-Stat, Statistics of Japan (https://www.e-stat.go.jp/en/); Hong Kong: Women and Men in Hong Kong - Key Statistics (2019 Edition); China: Lu, Jie-hua and Xiao-fei Wang (2013). Change of the Marital Status in Mainland China since1990s (in Chinese, 20世紀 90 年代以來我國婚姻狀況變化分析). Social Sciences of Beijing (北京社會科學). 2013(3): 62-72. Figure for 2015 comes from the National Bureau of Statistics, People's Republic of China.

regional variations in the timing and the prevalence of marriage, with later entry into marriage being observed more frequently in urban areas and in eastern China than in the rest of the country (Ji and Yeung 2014). Hence, even though the marriage patterns in China now seem quite different from the late, non-universal marriage patterns that characterise the other four East Asian societies, they might converge slowly in the years to come. However, a recent report from the New York Times suggested that instead of the Chinese government putting forth more measures to balance work and family, there has been "a resurgence in traditional gender roles that has increasingly pushed women back into the home" (Qin 2019). It remains to be seen whether fertility rates in China decline to even lower levels as increasingly well-educated Chinese women resist the pressure to marry.

\subsection{China as a special low-fertility case}

As the previous discussions indicate, the transition to below-replacement level fertility in China lacked many of the characteristics of this transition observed in other East Asian low-fertility regimes. These characteristics include a large share of women with tertiary education, a very late mean age at first marriage and a large percentage of women who had never married by age 50 . Rather than being similar to those of its East Asian neighbours, the historical marriage patterns in China since 1970 more closely resemble those in Southeast and South Asian countries 


\section{Figure 6:}

\section{Percentages of never married men and women at age 50}

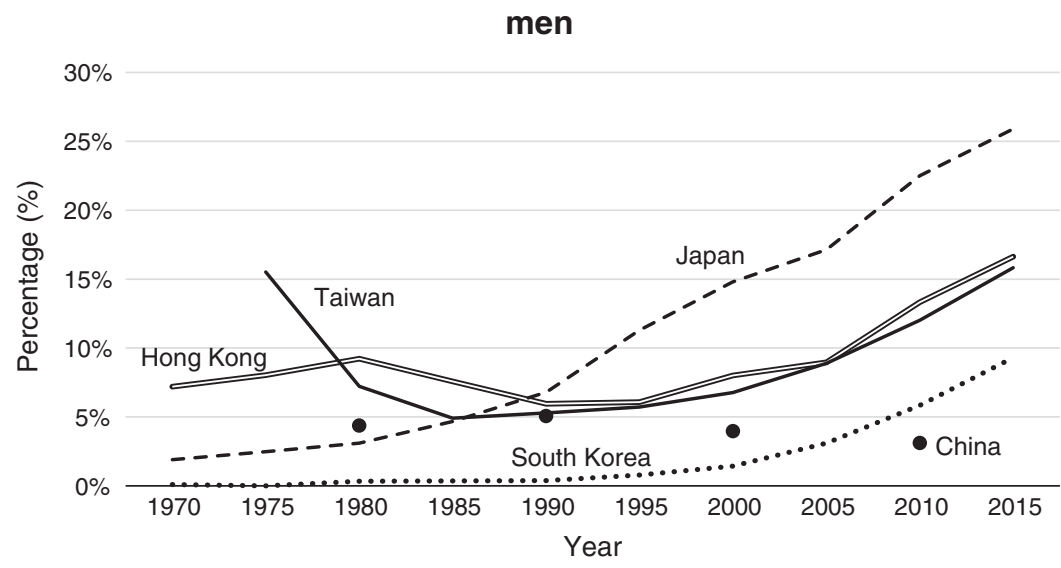

women

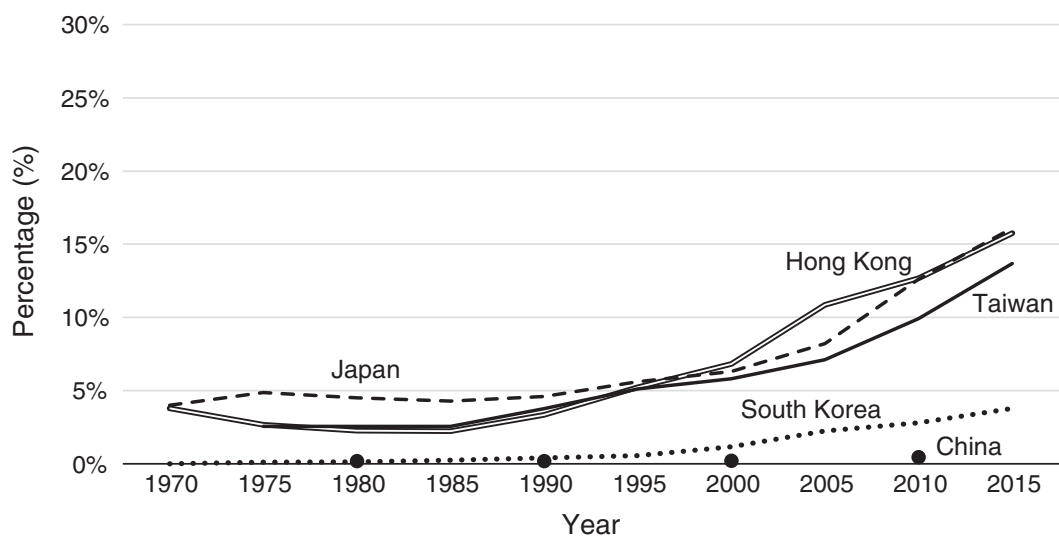

Source: Taiwan: figures taken from the Statistical Yearbook of Taiwan, 1975-2015; South Korea: statistics provided by Dr. Yoon-Jeong Shin, using the 2\% microdata of Korean Census data since 1970; Japan: figures taken from Population Census of Japan, Statistics Bureau, Ministry of Internal Affairs and Communications, Japan; Hong Kong: figures from the Hong Kong Statistics Database, Census and Statistics Department (https://www.censtatd.gov. hk/hkstat/index.jsp) and UN Database (Population by Marital Status, Age, Sex, and Urban/Rural Residence); China: figures taken from UN Database (Population by Marital Status, Age, Sex, and Urban/Rural Residence).

in terms of the mean age at marriage and universal marriage (Yeung et al. 2018). With regard to female empowerment, most low-fertility societies witnessed rising female labour force participation rates along with declining fertility rates, whereas China actually experienced the opposite pattern: FLFP in China decreased from about $90 \%$ in the 1960 s (due to state socialism) to about $60 \%$ in the late $2010 \mathrm{~s}$ (due to extended schooling), while over the same period, the TFR declined from six 
to 1.6 children. The initial stage of rapid fertility decline to sub-replacement levels in China also occurred during a period when the growth in women's educational attainment was limited. In terms of the socio-economic context, the GDP per capita in China is likely one of the lowest among all countries with similar levels of fertility. All in all, fertility decline to below-replacement levels in China took place within a unique set of structural conditions, which differed from the modernisation pathways of fertility decline observed in its East Asian neighbours. That is, prior to the implementation of the one-child policy in 1979, a dramatic decline in fertility from 5.8 to 2.8 children occurred that was largely driven by the strong enforcement of the later-longer-fewer state policy (Cai 2010; Peng 1991) during a time of relatively low economic development (Attané 2002; Peng 1991). While the fertility transition has progressed much faster in urban than in rural areas since the $1960 \mathrm{~s}$, some scholars have suggested that economic development played a non-negligible role after the 1980s in further depressing fertility to sub-replacement levels (Poston 2000; Cai 2010; Gietel-Basten and Cheng 2019), even though others have disagreed (Goodkind 2017).

\subsection{Uniqueness of East Asian fertility patterns}

In addition to being characterised by the rapid transition from a high-fertility region during the mid-20th century to a region with ultra-low fertility rates at the turn of the millennium, the fertility patterns in East Asia have a few more unique traits: skewed sex ratios at birth ${ }^{4}$, low rates of non-marital birth, rising prevalence of bridal pregnancies and relatively low rates of cohabitation.

\subsubsection{Skewed sex ratios at birth (SRB)}

High sex ratios at birth largely started emerging in different regions around the globe since the 1980 s, when sex-testing techniques became more widely available. Female foetuses are thus selectively aborted in many countries with patrilineal family systems, such as the Caucasus and parts of South Asia (especially India), East Asia and Eastern Europe (Guilmoto 2015). As Figure 7 shows, China (Goodkind 2011), Hong Kong (Basten and Verropoulou 2013) and Korea are three societies in this region with more extreme sex ratios at birth that once exceeded 115, although the SRBs in Korea normalised after 2007 (Choi and Hwang 2020; Den Boer and Hudson 2017). The SRBs have been a bit less distorted in Taiwan, where they rose above 110 for a few years. Japan stands out as the only country in East Asia that has not had imbalanced sex ratios in recent years, even though there

\footnotetext{
4 Japan is an exception, although historical evidence has revealed that there was a male surplus in pre-modern times (Caldwell and Caldwell 2005).
} 
Figure 7:

Sex ratios at birth in five East Asian societies since 1970

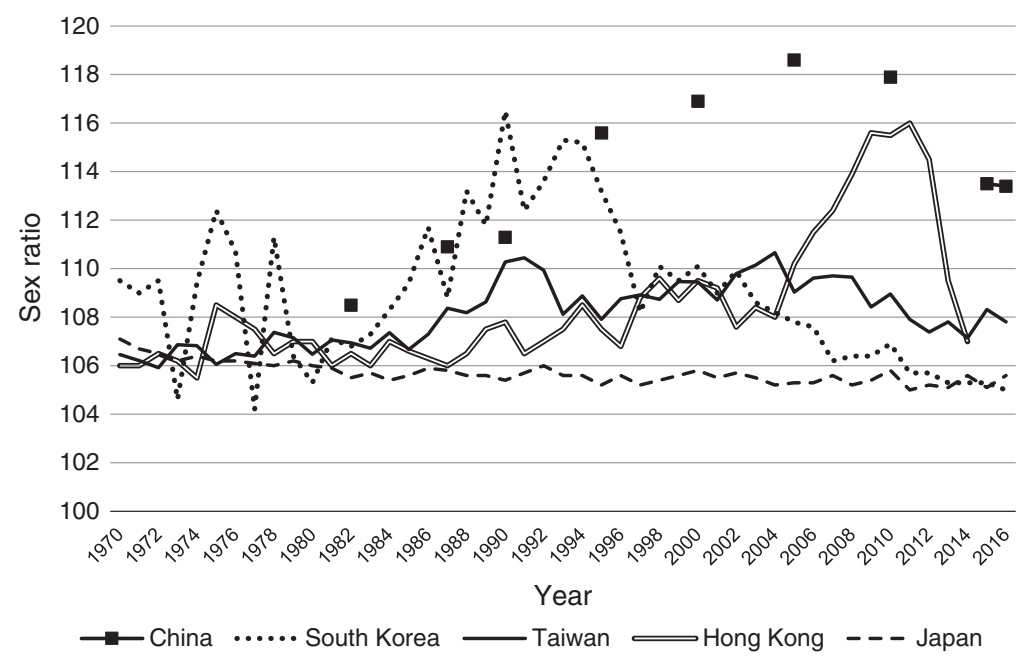

Source: Department of Household Registration, Taiwan; vital statistics of Japan and South Korea; Hong Kong vital registration data and Chao et al. (2019); UNICEF database (https://www.unicef.cn/en/figure-19-sex-ratio-birth19822017) for China.

is historical evidence of distortions in Japan, such as of excess male infants due to the prevalence of female infanticide during the Tokugawa period in pre-modern Japan (Caldwell and Caldwell 2005; Drixler 2013). Although the scope of the male surplus at birth may appear slightly less alarming in Taiwan, Hong Kong and Korea than in China, the fact that sex ratios at birth initially rose with the expansion of women's educational and occupational attainment over the past decades has made the situation in these three societies more disturbing than it is in China or India, where women's socio-economic attainment progressed much more slowly than it has in these more advanced East Asian economies. In contrast, Asian societies with a bilateral kinship system (in which descent and inheritance are passed equally through both parents) are much less likely to have skewed sex ratios at birth. This is the case in much of Southeast Asia (Yeung et al. 2018), even though Singapore and Vietnam are two exceptions because of their Confucian heritage.

\subsubsection{Low rates of non-marital birth}

Contemporary fertility patterns in East Asia are also characterised by a low percentage of births outside of marriage, which is in stark contrast with the patterns observed in many Western developed societies. According to the latest statistics, the 
share of non-marital births is about 1.5\% in Korea, 2\% in Japan and 4\% in Taiwan (Raymo et al. 2015). Hong Kong has a slightly higher proportion of non-marital births at 8\% (OECD Korea Policy Centre 2018; Gietel-Basten and Verropoulou 2018). While there are no statistics for extra-marital births in China, there are good reasons to believe that the share in that country is also extremely low because of the traditional family values and the social stigma attached to such births in Chinese society. A substantial increase in non-marital childbearing in East Asia is unlikely in the foreseeable future, as the shares of non-marital births in these countries have been increasing very slowly since the 1970 s, shifting from $2 \%$ to $4 \%$ in Taiwan and from $1 \%$ to $2 \%$ in Japan (The National Institute of Population and Social Security Research 2018). Overall, childbearing is not an option for many unmarried women who want to have children in East Asia, because having a non-marital birth brings disgrace upon the family.

The persistent low period fertility rates observed in East Asia represent the combination of a strong tempo effect and a fertility-suppressing quantum effect that comes from declining marriage rates. From a cohort perspective, the completed fertility levels of married women remained at about two children for the cohorts born in the 1960s and the early 1970s in Taiwan (author's own calculations using the 2012 KAP survey) and for the 1960s birth cohorts in Japan (The National Institute of Population and Social Security Research 2018). However, the CTFR for the late 1960s birth cohorts are just 1.8 in Taiwan and 1.5 in Japan due to increasing childlessness resulting from non-marriage. Hence, even if all delayed marriages (and thus births) could be recuperated at older ages by late-marrying women, the increasing share of women who remain single beyond their reproductive ages across cohorts will make a reversal in fertility rates a challenging goal. This pattern is very different from the trends observed in European low-fertility societies, where decreases in fertility rates associated with declines in marriage have often been offset by sizeable shares of births out of wedlock. This being the case, one might wonder how such low rates of non-marital births square with rising sexual freedom and delayed marriage among young adults in East Asia. Indeed, when pre-marital pregnancies do occur, the common practice in the region has been to legitimise the births through matrimony, although many unplanned pregnancies might have been aborted.

\subsubsection{Rising prevalence of bridal pregnancies}

Figure 8 shows the share of bridal pregnancies (or "shotgun marriages") since 1970. Most studies define bridal pregnancies as births that occur within eight months after the date of marriage. Due to differences in analytical methods and data formats, the lines in Figure 8 reflect the share of bridal pregnancies by either marriage cohort or birth cohort. The prevalence of bridal pregnancies has been rising in recent decades in all of these societies, ranging from about $10 \%$ of births in Hong Kong to as high as one-third of births in Taiwan. However, while bridal pregnancies are becoming increasingly common, what percentage of pre-marital conceptions end in abortion remains unclear, even though a recent report has estimated that $33 \%$ 
Figure 8:

Percentages of bridal pregnancies by birth or marriage cohorts

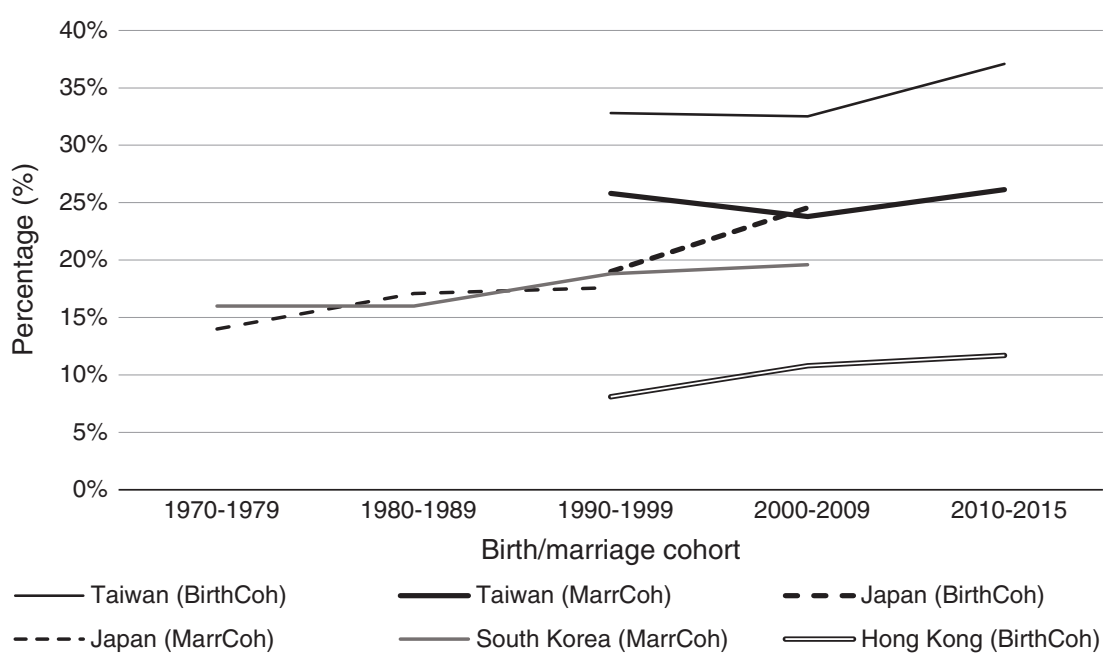

Source: Birth registration data and Statistical Yearbook of Taiwan; Kim and Lee (2018); Iwasawa and Kamata (2014); Ministry of Health, Labor and Welfare https://www.mhlw.go.jp/toukei/saikin/hw/jinkou/tokusyu/syussyo06/ syussyo2.html\#02; Gietel-Basten and Verropoulou (2018).

of all pregnancies in East Asia in 2010-2014 ended in abortion (The Guttmacher Institute 2019). The patterns described here point to the persistence of cultural norms that place a high value on female chastity, see marriage as the ideal context for childbearing and strongly disapprove of non-marital births. This is a vivid example of a region where the modernisation narrative - i.e. that family diversity and unconventional family practices tend to follow economic development - does not hold. In the case of East Asia, it appears that conventional family practices are rather deeply ingrained.

\subsubsection{Relatively low rates of cohabitation}

With pre-marital pregnancies surging over the years, it seems reasonable to assume that the prevalence of cohabitation has been increasing as well. While cohabitation in East Asia appears to be more common than it was in the past, levels of cohabitation are still much lower in the region than they are in most of the other highly developed countries. Indeed, cohabitation remains a frowned-upon living arrangement among many Asian parents. Thus, when young adults move in with a partner, they often have to conceal it from their parents. The unconventionality of cohabitation is further reflected in the fact that statistics on cohabitation are not 
Figure 9:

Percentages of ever cohabited among all women by birth cohort

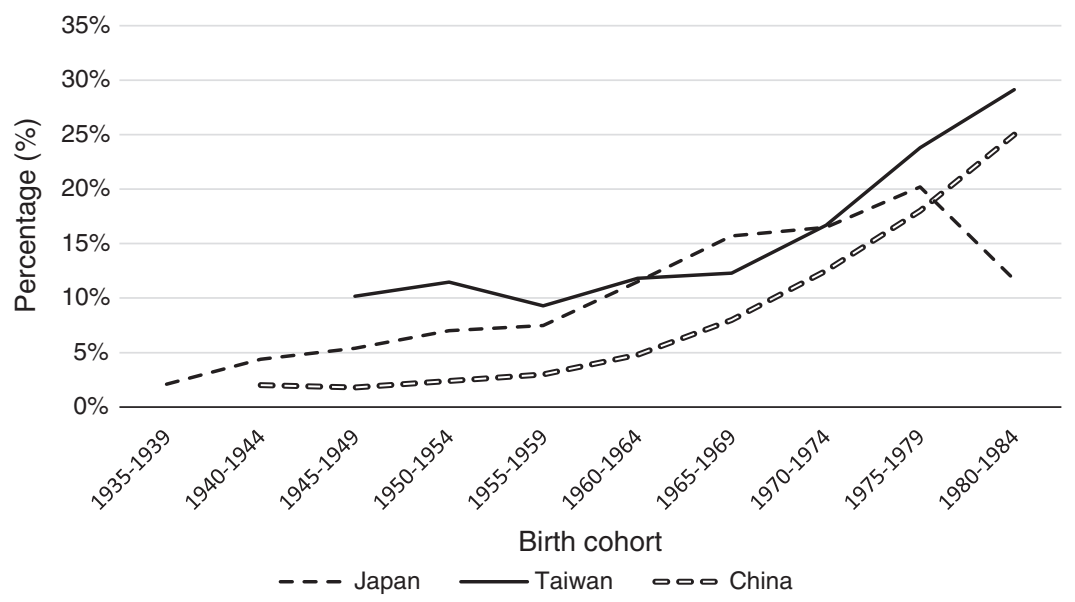

Source: Author's own calculations from KAP survey of Taiwan, 1998 and 2012; Tsuya (2006); Yu and Xie (2015).

always readily available in this region. For instance, there seem to be no reliable cohabitation statistics for Hong Kong or Korea (Yoo 2015). It has been estimated that in 2004, the period rates of ever experiencing cohabitation were $10-15 \%$ in Japan and roughly 20\% in Taiwan (Lesthaeghe 2010; Raymo et al. 2009). From a cohort perspective, the prevalence of cohabitation has been rising steadily in Taiwan (author's own calculations based on the 1998 and 2012 KAP surveys), Japan (Tsuya 2006) and China (Yu and Xie 2015) among women born after 1950 (see Figure 9).

Although the prevalence of cohabitation is unknown in Hong Kong, a report from the The Family Planning Association of Hong Kong (2017) indicated that the share of young adults aged 18 to 27 who agreed with the statement "I will cohabit before marriage" had increased from $13 \%$ to $24 \%$ among women and from $21 \%$ to $34 \%$ among men between 1996 and 2016. In Korea, public opinions regarding cohabitation remain relatively reserved and conservative. A survey of 253 cohabiting men and women in Korea aged 18-49 found that nearly 89\% believe that Korean society is not favourable towards unmarried cohabitation (Byoun 2017). Moreover, the social stigma associated with cohabitation appears to be highly gendered in Confucian Korea: cohabiting women are perceived negatively because of concerns about female chastity and virginity, whereas cohabiting men are considered unfilial for failing to continue the family lineage through marriage (Yoo 2015).

The four unique characteristics of East Asian fertility mentioned above are closely linked to a patriarchal structure based on family lineage through sons, strong parental authority, an emphasis on women's chastity (i.e. sanctions for pre-marital 
sex and "illegitimate" births outside of marriage) and the belief that women are obliged to bear sons to continue the patrilineal bloodline. In the next section, we will outline the commonly studied causes of East Asian low fertility, followed by a more focused discussion of how Confucian culture in the region supports the persistence of a patriarchal family system and a social context that emphasises credentialism through heavy investments in education and exam preparation. Both of these factors have made childbearing and childrearing burdensome for the younger generations.

\section{Causes of ultra-low fertility in East Asia}

\subsection{Existing explanations}

Since fertility in East Asia dipped below replacement level, a growing literature has sought to provide explanations for the rapid and pervasive changes across the region (Feeney 1994; Jones 2007, 2013; Straughan et al. 2008; Frejka et al. 2010; Ogawa and Shah 2015; Gietel-Basten 2018; Poston 2000). Some of the most common explanations include industrialisation and rapid economic development, educational expansion and increasing labour force attachment among women, the introduction of effective family planning programs, the lack of sufficient welfare policies that support families and a globalised economy that brings rising uncertainties for the younger generations. The first three factors have been linked to marital fertility decreasing to near-replacement levels in the initial stages of the fertility transition; while the last two factors have become more salient as fertility levels have declined to ultra-low levels.

Indeed, industrialisation fuels the demand for skilled labourers, which often leads to educational expansion, and which, in turn, increases women's labour force participation in market economies. Higher levels of labour force attachment cause people to delay marriage and thus shorten their reproductive life span. The market economy has also led couples to prefer a smaller family size, shifting their focus to child "quality", and to the ability of their children to compete in education and employment. Changes in the timing of marriage and in the desired family size have both contributed to a decline in fertility levels. In addition, as women gain economic independence, their mating preferences and marriage expectations tend to change, which leads to more lifelong singlehood and further fertility declines in contexts in which non-marital births are limited. After years of delayed and decreased childbearing, whether there is an eventual rebound in fertility and whether there is a pervasive decline in family size become the key factors that differentiate societies with near-replacement fertility levels from societies with sustained very low fertility levels. In such contexts, adequate government support for families also becomes of paramount importance.

Young adults in many low-fertility countries are discouraged from having children by insufficient family support from their governments, precarious labour market 
conditions and economic instability in a globalised world. While stable employment and income accumulation remain important prerequisites for family formation in East Asia (Fukuda et al. 2020), more and more young adults are taking a longer period of time to establish themselves as "ready for marriage and parenthood"; particularly men, who are still expected to be in good economic standing to be considered marriageable partners (Yoshida 2017). When these pressures are combined with the lack of affordable housing in major East Asian cities (McDonald 2009), it is clear that family formation is becoming more arduous for young adults. Governments in East Asia have been particularly sluggish in formulating pronatalist family and labour policies that would alleviate the burden of childbearing and childrearing faced by parents. This is because caring for the young and the old has long been considered a family responsibility in collectivist societies. Moreover, the initial social responses to fertility decline in patriarchal societies are often to blame young people, and especially young women, for not fulfilling their duties. These mentalities and ideologies represent additional fertility-suppressing contextual and cultural factors that keep certain societies trapped in very low fertility for prolonged periods of time. In other words, limited state support for families provides only a partial explanation for why East Asian countries have lower fertility than other countries with similar policies, such as the German-speaking countries and Southern Europe. In East Asia, an ingrained Confucian culture that embraces patriarchy and credentialism appears to be at the root of declining marriage rates (and childbearing incentives), and the high cost of raising children seem to be directly or indirectly linked to the region's current low fertility levels. In the next section, we will probe these issues further by tracing the historical origins of Confucian influences that shape the social ethos in East Asia, and by examining the question of how this cultural milieu influences social and individual adaptations to rapid demographic transitions.

\subsection{Confucian culture: patriarchy and credentialism}

The teachings of Confucius have influenced Chinese society for more than 2000 years, since Confucianism became the official state religion and national ruling ideology during the Han dynasty (206 B.C. -220 A.D.). These teachings provide ethical and moral principles for social relationships and political governance in an imperial context. These principles serve as the core foundation of all interpersonal relationships and consolidate the legitimacy of the ruler (emperor). Interactions within the family and in the workplace are regulated by Confucian doctrines as hierarchical and patriarchal (Jackson et al. 2008). These teachings also gave rise to an exam-driven educational system, which used to be crucial for recruiting civil servants into the central government. As fame and fortune was increasingly attached to civil servant positions, the pursuit of secular success through academic excellence became highly valued in China (Weber 1958). 


\subsubsection{Patriarchy}

The family systems in Confucian societies share a number of key characteristics. On the one hand, the patrilineal kinship system practices patrilocality as a normative post-marital living arrangement. A woman typically moved into the home of her husband's family after marriage and shouldered the responsibility of taking care of her parents-in-law. As inheritances were passed down to sons, a strong preference for sons became the norm. Thus, parents had few incentives to invest in their daughters, particularly in agrarian contexts. As sons were given more educational opportunities than daughters, many women were illiterate and uneducated. Since women lacked education and employment opportunities outside of the natal home, marriage became the expected "career" for women, and took place quite early in adolescence. In addition, the emphasis on chastity and virginity encouraged early marriage and further limited women's life course development. In such societies, women had limited agency, and their lives were largely confined within the domestic sphere. Thus, for a woman, housekeeping and childrearing were considered her primary lifelong responsibilities, and how well she fulfilled these tasks in the eyes of her family often defined her status in old age. Even today, many families still treat sons and daughters differently, though they may be given similar educational opportunities.

On the other hand, the Confucian family system is also based on a patriarchal order that closely monitors the decisions and behaviours of the young and women (Jackson et al. 2008). Children are expected to obey their parents. These hierarchical parent-child relationships form the core of "filial piety", which is considered virtuous, and has been instilled in generations of young children. It is expected that the parents' opinions and decisions regarding key events in the lives of their children, like marriage, will not be challenged. In addition, married young women occupy a subordinate position in the family, and it is traditionally considered virtuous for a woman to obey her parents-in-law and her husband. In both the pre-modern and the modern era, a married woman could be expelled from her marital home if she acted against the wishes of her parents-in-law or husband. An expelled woman is considered a disgrace to her natal family, and generally receives no support. In fact, the teaching of the "three obediences" for women makes clear the role a woman is expected to play throughout her life: i.e. a woman should obey her father as a daughter in the natal home, her husband as a wife in the marital home and her son(s) in widowhood. This teaching has cast a long shadow over women's status in Confucian societies. In contemporary East Asia, the happiness of a married woman often depends on her relationship with her parents-in-law, which can be tough to manage when intergenerational value clashes occur.

\subsubsection{Credentialism}

The legacy of Confucianism was perpetuated through competitive imperial civil service examinations over a period of around 1000 years. Since the 6th century, the 
classical texts have been the contents of state examinations. Confucius temples were set up to teach Confucian classical texts, which had been essential to the education of the elite class in China. Later on, during the Song dynasty (960-1279 A.C.), the imperial examinations became more institutionalised and levels of fairness and competitiveness increased. Thus, among generations of Chinese people, social mobility through civil service examinations came to be seen as a route to success. The legacy of these exams has continued to shape how education is designed and delivered in contemporary periods. This 1000-year-old state examination system has contributed to the homogeneity and the stability of Chinese civilisation, and it has also contributed to the belief in credentialism.

The profound historic influence of the civil service exam is still evident today in the pervasive embrace of credentialism and the low regard for vocational education and craftsmanship in Confucian societies. Academic success in the educational system is considered a life goal that is of paramount importance in numerous families, with parents doing their best to make sure that their children advance as far as possible academically. As Max Weber (1915) once pointed out, "For twelve centuries social rank in China has been determined more by qualification for office than by wealth" (Weber 1958). In the ancient past, the poor and the rich were equally eligible to compete for a few coveted government positions that guaranteed a lifetime of prestige and prosperity. The successful exam-takers were rewarded with tremendous social status and wealth in a system that was designed to promote social mobility and to give rise to an elite class of scholar-bureaucrats or literati. This elite class was held in high regard, and was looked upon much more favourably by the public than farmers, merchants, engineers, or artisans. The high status of this class is reflected in a common saying that goes, "Scholarship pursuit surmounts all other occupations". As a result of this history, credentialism has become an integral part of the East Asian mentality, with academic performance being seen as the path to secular success.

\subsection{The impact of Confucianism}

The influence of Confucianism on social and family relationships, as well as its emphasis on exams and education, spread beyond the borders of China and reached the nearby countries of Japan and Korea around the third and fourth centuries. The institutional diffusion of Confucianism has left an indelible imprint on the social, psychological and educational systems in larger East Asia, and it explains why the family practices and educational systems in the five societies under discussion share so many common traits. The Confucian model of higher education that prevails in contemporary East Asia (Marginson 2011) refers to a state system of examinations and mass education that has reinforced families' long-standing commitments to education, and that has provided the skilled labour needed for economic growth. In the following sections, three issues related to the Confucian patriarchy and credentialism will be further discussed as proximate 
determinants of the decades-long low fertility levels in East Asia. That is, the ingrained patriarchal mindset in East Asia has made changing the traditional domestic division of labour a rather slow process and has reduced the efficiency of pronatalist policies. The belief in credentialism has placed considerable pressure on new parents in post-industrial societies in which the costs of education and childrearing are high, and competition in the labour market is becoming ever fiercer.

\subsubsection{Women's role at home}

In East Asia, a gendered division of labour has persisted in the modern era, even as women's levels of education and labour market participation have increased sharply. In the past, when women had much less education and far fewer career prospects than men, the life course of the great majority of women was defined by their role as a housekeeper. Even today, the arrival of a new-born in a family substantially increases the woman's domestic workload, while it rarely affects the man's share of the domestic tasks (Gjerdingen and Center 2005; Kim and Cheung 2019). Despite their rising socio-economic status in recent decades, women have continued to shoulder the bulk of domestic chores in all five East Asian societies (Figure 10). While progress towards a more egalitarian division of labour has occurred, it has been slow. In 2016, married women in East Asia were, on average, still performing between two-thirds (Hong Kong) and 85\% (Korea) of all domestic chores.

In addition to the double burden of work and family, the persistence of a preference for sons is another source of role strain for married women in contemporary East Asia. For instance, even though the overall sex ratios at birth in Taiwan have decreased from a high of 111 to 107 in recent years, the sex ratios for parity 2 and parity $3+$ births are as high as 108-109 and 113-115 among tertiary-educated women born in the 1970s and 1980s. Moreover, these figures are even higher among women without tertiary education (author's own calculations based on the Taiwanese birth register data). In other words, some of the best-educated women in Taiwan who would appear to be more empowered by their socio-economic attainment have been unable to avoid perpetuating such practices.

Given how much educational and occupational progress women have made in recent decades, it seem inevitable that the persistence of a gendered division of labour and the pressure to bear sons create work-family role strain. Many women feel forced to choose between career and family, as they are offered few options for combining the two. In light of the numerous familial obligations that are imposed upon women after they get married, it is no wonder more and more East Asian women are deciding to opt out of the entire "marriage package" (Bumpass et al. 2009).

In the advanced East Asian economies of Japan, Korea and Taiwan, it is not only the native-born women who are having fewer children, but the many foreign brides who have married native-born men (often with lower socio-economic status). It appears that the arrival of these migrant women has not alleviated the very low 
Figure 10:

Women's share of total housework hours

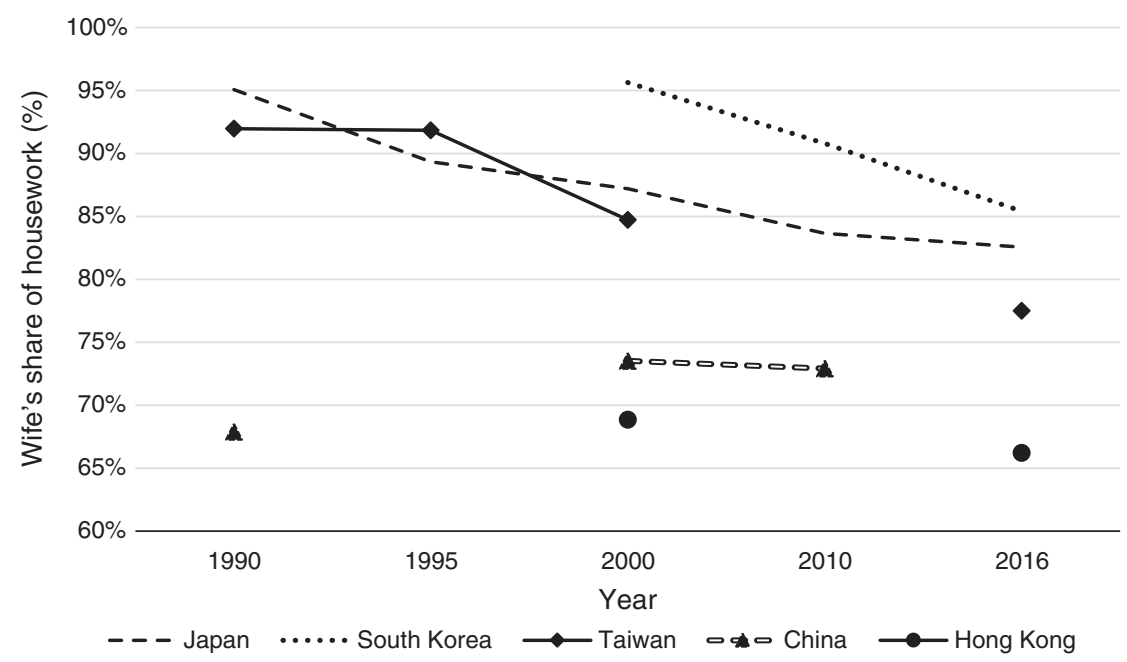

Source: Hsiao (2005); Hsu (2008); Kim (2017); Survey on Time Use and Leisure Activities (1996, 2001, 2006, 2011, 2016), Japan; Yang (2017).

fertility in their host countries. Despite the common public perception that migrant women have high fertility, the evidence indicates that in these three countries, foreign brides have fewer children than native-born women (Ishikawa 2015; Kim 2018; Yang et al. 2012). Given that these migrants often have at most a high school degree and limited career prospects, it is rather paradoxical that their fertility rates are lower than those of native-born women, who likely have more workfamily conflicts. The research on this issue has observed that foreign brides often experience conflicts stemming from discriminatory treatment (Lee 2016; Yang et al. 2012), such as the patriarchal expectation that they will bear children combined with social prejudices about the "quality" of their offspring (Hsia 2007). In addition to living in a low-fertility context, these conflicts could make it difficult for migrant women to have more children, and could partly explain their low fertility.

\subsubsection{Efficiency of pronatalist policies}

East Asian governments in general have been slow to adopt pronatalist policies. This hesitation is partly rooted in their collectivist attitudes and commitment to strong family structures; i.e. the belief that the responsibility for child care should fall on the shoulders of family members (particularly women) and not on the government. Paid parental leave policies started appearing in most East Asian countries roughly two to four decades after the TFR dropped below replacement level: in 1996 in 
Japan, in 2001 in Korea and in 2009 in Taiwan. Over the years, parental leave provisions have become more generous, with the pay scale and the length of leave benefits gradually increasing in Japan, Korea and Taiwan (Lee and Lin 2016; Sano and Yasumoto 2014; Lee 2009). While maternity leave was introduced earlier than paternity leave in Japan and Korea, the two countries now have among the most generous paid paternity leave policies (i.e. 52 weeks) in the OECD (OECD 2019).

Although government investments in these pronatalist policies have been increasing, the uptake of leave has been extremely low among fathers, and, at times, even among mothers. This is likely due to traditional values regarding the gendered division of labour, the fear of repercussions from employers, and the fact that it is more "costly" for men to take parental leave because of the gender wage gap. These rigid labour market structures and workplace norms often force new parents to continue to work long hours, and deter them from taking parental leave (Brinton and Oh 2019). These lower leave uptake rates have further perpetuated the gendered division of labour, and have, in turn, reduced women's (mothers') intentions to have (more) children. By 2017, the paid parental leave uptake rates among eligible mothers were $83 \%$ in Japan, $76 \%$ in Taiwan and only $22 \%$ in Korea. In stark contrast, the share of eligible fathers who used parental leave in 2017 was a mere 3\% in Japan, 5\% in Korea and 8\% in Taiwan (The Ministry of Health Labor and Welfare 2019; Ministry of Employment and Labor 2019; Ministry of Labor 2019). The low levels of leave uptake among mothers and fathers in Korea are particularly striking, and suggest that the country has a workplace culture that discourages new parents from enjoying such benefits. Indeed, past research has shown that the institutional culture in companies and the prevailing social values are the main impediments to higher rates of leave use in Japan and Korea (Brinton and Mun 2016; Mun and Brinton 2015; Steger 2018). Moreover, it appears that parental leave policies have led to "negative compliance" among some Japanese firms, which have reduced the number of women they recruit in response to growing family leave requirements (Mun 2015).

\subsubsection{The burden of human capital investment}

Even though the majority of East Asian societies have greatly modernised and now have a much more diversified occupational structure than is found in feudal and agrarian contexts, many parents still consider academic excellence a necessary condition for having a successful and happy life. The rise of the knowledge economy has only intensified the perceived need for academic achievement. The cultural and historical ethos of family commitments to education are realised through contemporary exam-driven education. This system is at the root of some recent efforts to explain very low fertility in the region, such as claims that these societies have "education fever" (Anderson and Kohler 2013), are engaged in an educational "arms race" (Jones 2019) or are "success-oriented" (Ogawa et al. 2015). Coupled with the collectivist culture in this region, East Asian parents are often 
held responsible for their children's school performance, which is linked to the "face" of the family. Hence, parents are expected and willing to invest considerable financial resources in their children's education. In the early 2000s, the shares of total per capita educational costs for children and youths under age 24 that were paid for privately by parents reached as high as $50 \%$ to $70 \%$ in Taiwan, Korea and China (Ogawa et al. 2015). Moreover, families in East Asia pay much larger shares of the costs of tertiary education than their counterparts in other OECD countries (Marginson 2011).

Investment in education can be multi-dimensional. Due to the legacy of a classicaltext learning culture, the school curricula in East Asia often follow a standardised program with well-defined materials for each subject field. Students are expected to show their mastery of these materials in exams. Helping their children improve their learning outcomes by enrolling them in after-school shadow education (i.e. cram school) is considered indispensable by many parents. In addition, as participating in extracurricular activities boosts the chances of university admission, parents often invest heavily in their children's education outside of school. All of these efforts are centred around preparation for the university entrance examination, which is a particularly stressful and competitive process for parents and children alike. While preparing for these exams can be very arduous, students who excel in them are admitted to prestigious elite universities, which can bring tremendous joy and glory to their families. Although public education in most East Asian societies is not costly, the large human capital investment parents often make in their child's shadow education, extracurricular activities and private university tuition (if the child is not admitted to a public university) mean that having children is a long-term financial burden for parents. These costs inevitably enter into couples' calculations when they are considering having children.

Indeed, existing research has indicated that spending on children is negatively associated with period total fertility rates in Japan, Korea and Taiwan (Ogawa et al. 2015). In particular, there is evidence that a decrease in the TFR leads to little change in the total cost of childrearing per adult, which suggests that there is a strong quality-quantity trade-off in fertility behaviours among East Asian parents. It has also been shown that private transfers to children and youths increased substantially from the mid-1980s to the mid-2000s in East Asian countries (Ogawa et al. 2015; Tung 2011). Thus, it appears that when living standards, education expenses and employment instability in a globalised economy are all high, fertility intentions are substantially attenuated.

\section{Social changes in Confucian societies}

Based on the patterns and causes of East Asian fertility decline discussed above, we can argue that the very low fertility levels in the region are largely the result of both continuity and changes in traditional values. On the one hand, Confucian patriarchal values still strongly influence people's decisions surrounding intimate 
relationships and family formation, such that non-marital birth rates and the prevalence of cohabitation have remained very low. The underlying mindset is characterised not only by an emphasis on women's chastity, but on marriage as the ideal setting for childbearing and childrearing. On the other hand, in recent decades, attitudinal changes have been taking place across these societies to varying degrees and particularly in terms of people's views on women's roles, marriage, marital childbearing and old-age support. The analyses that follow will show that common public discourses asserting that young people have low fertility intentions because they are selfish and materialistic perpetuate myths, and do not accurately reflect young people's values. In fact, many of these discourses are still based on Confucian moral codes, even though these teachings have become increasingly incompatible with the rapidly changing world young people are now facing.

Using data drawn from the 2006 and 2016 East Asian Social Survey ${ }^{5}$ (EASS), Table 2 shows the percentage of respondents of marriageable ages (i.e. aged 20-49) who agreed with eight statements about marriage and family values. The response values are on a seven-point scale, ranging from strongly disagree $(=1)$ to strongly agree $(=7)$, with neither agree nor disagree $(=4)$ in the middle. Hence, the figures in Table 2 (percentage of respondents agreeing with a statement shown) refer to those who answered with values ranging from five to seven. The two survey years of 2006 and 2016 are the only two time points when the EASS family modules were administered.

Although the public opinions revealed in Table 2 reflect changes over one decade only, they offer comparable attitudinal measures for four East Asian countries with a Confucian heritage. We can see that, overall, family values were shifting towards more liberal attitudes, even though they fell short of catching up with the speed of women's socio-economic progress. The figures show that attitudes towards gender roles (item 1), union formation (items 2-4) and childbearing (items 5-6) had become more non-traditional, even though the attitudinal changes in family obligations (items 7-8) were relatively minor. As fewer respondents endorsed the traditional breadwinner-housekeeper model, more respondents also considered cohabitation without a marriage plan an acceptable option. Moreover, married people were not rated as happier than singles. Levels of acceptance for childless marriage increased, while the preference for sons declined over time. The pace of change in views about cohabitation and childless marriage is particularly notable. Among the four East Asian countries studied, the South Koreans stand out as having the most traditional attitudes and adhering to more conventional family values, while also displaying the most rapid attitudinal changes on the first six of these eight items. These findings are in line with the results showing that the percentage of Korean men and women who were lifelong single also began to increase later and rose

\footnotetext{
5 The EASS is a cross-national and biennial social survey project that aims to promote comparative studies on social lives in East Asia. Since it was launched in 2003, the EASS has completed two waves of family surveys.
} 


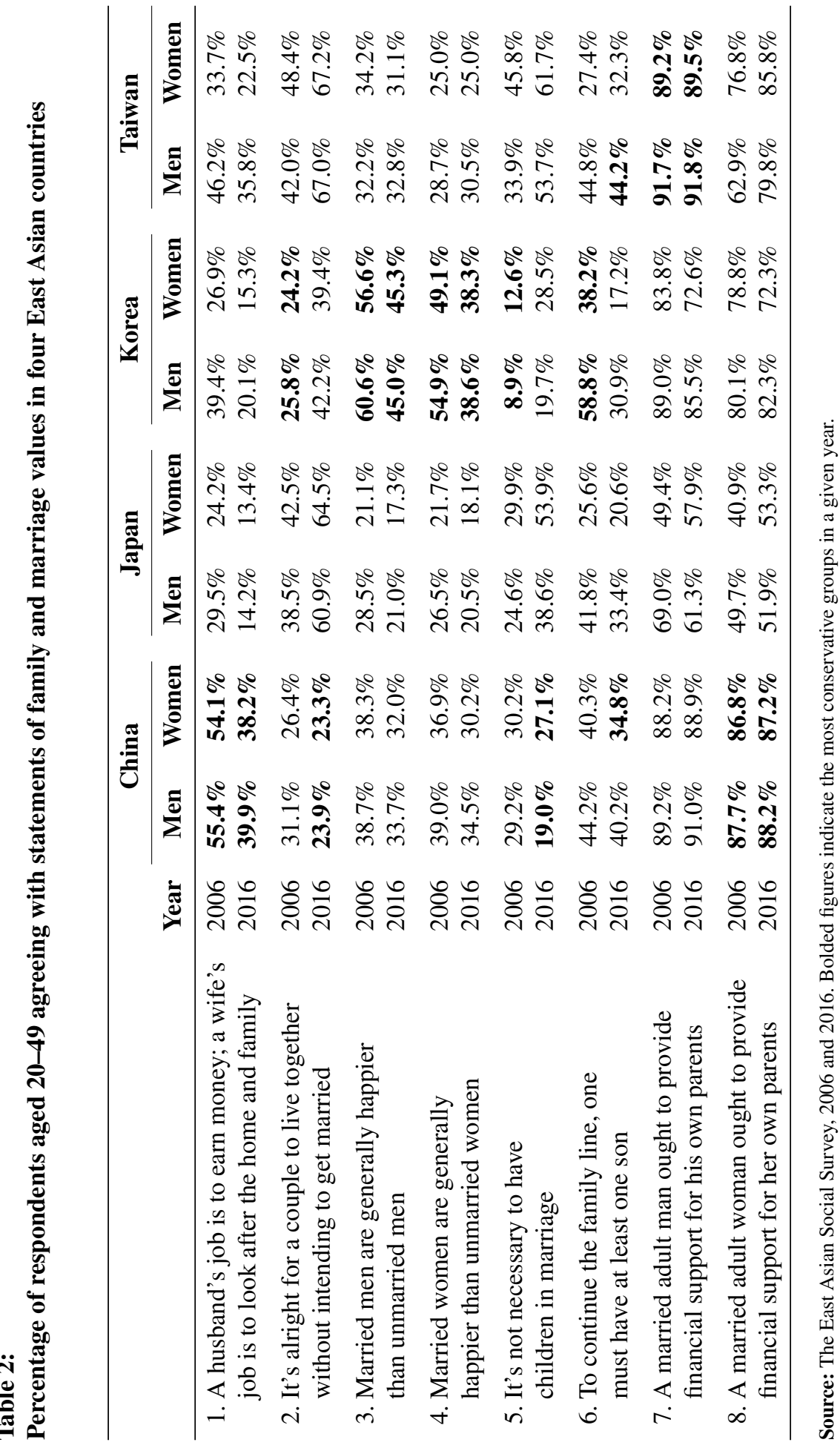


more slowly than it did the other three advanced East Asian economies in Figure 6; and that Korean women still shoulder $85 \%$ of total household chores, which is by far the highest level among the five societies analysed in Figure 10. In addition, both the unavailability of cohabitation statistics (Yoo 2015) and the very low non-marital birth rates (Raymo et al. 2015) in Korea point to the stigma and the undesirability of non-conventional family formation in that society. The highly traditional social milieu in Korea stands in stark contrast to the remarkable rise in the percentage of tertiary-educated Korean women aged 25-29, as shown in Figure 3. This is likely one of the key factors driving attitudinal changes and the reason why the TFR keeps declining in South Korea, reaching a record low of 0.92 children per woman in 2019 , despite the government's heavy investments in various pronatalist policies since the turn of the new millennium (Lee and Choi 2015). In short, when a society retains views on women's roles that originated in a context in which women were less educated and had limited career prospects, younger cohorts of well-educated women will inevitably face more repercussions when they attempt to pursue nontraditional life goals. This certainly has implications for their family behaviours, because they might be considered less desirable potential marriage partners and mothers and have to shoulder much higher opportunity costs of childbearing.

\section{Recent policy responses and the future of fertility in East Asia}

Even though the fertility transition to below-replacement levels occurred later in East Asia than it did in most of the Western developed countries, the speed and the scope of these demographic changes have been greater in East Asia than they were in the West. While it took about 50 to 80 years for Western developed nations to reach the threshold of people aged 65 or older making up $20 \%$ of the population, Japan took only 33 years to reach this point, and it could take even fewer years for Taiwan and Korea to reach this threshold. Except in China, where marriage remains near-universal for women, the ultra-low fertility levels in East Asia were initially driven by declining marital fertility rates and delayed childbearing, and then by decreasing marriage rates in the absence of non-marital births. Along with the persistence of patriarchal culture, the high costs of raising children and the limited availability of public child care have led people in East Asia to have fewer children and to form fewer marital unions than in the past. The shares of women who were still single at age 50 have been rising since the 1990s in all advanced East Asian economies (and in Japan, since 1970s) (Figure 6). Thus, how fertility in this region develops in the future will be influenced by the evolution of matrimonial behaviour over time, and by whether attitudinal changes de-stigmatise non-marital childbearing.

It appears that one of the reasons why so many young people stay unmarried is that they feel they are neither able nor ready to have children. This could be 
because the direct costs of childrearing are too high, or simply because they want to stay away from a patriarchal marriage system that is too stressful and involves too much personal sacrifice. The high costs of raising children can be ameliorated by providing child care subsidies, inexpensive public child care, or even free education, and by implementing more comprehensive economic policies that help young workers escape the low-wage trap they are currently facing in East Asia. But changing the marriage system is hardly attainable by policies alone. Given that childbearing is considered an unquestionable moral duty in patrilineal East Asia, newlywed couples often get bombarded with inquiries about their childbearing plans by parents and family members from both sides. This can be stressful for men and women who are employed in competitive market economies, and particularly hard to bear for women in families in which there is a strong preference for sons. In the case of Taiwan, the sex ratios at birth are still 108-109 for parity 2 and 114 for parities 3 and above, even among the younger cohorts born in 1980-1989 (author's calculations using birth register data in 1998-2016). Hence, when we look at why marriage rates have been declining in recent decades, it becomes clear that the social mentality and the prevailing norms about marriage and childbearing are incompatible with the empowerment and the rising agency of women. Young adults in East Asia should be given more flexibility to form families: i.e. partnership formation, marriage and childbearing should have no strictly defined timing or order; and these events should promote, rather than attenuate, their personal wellbeing.

In addition to suffering from norms of gender inequality and relatively rigid life choices, women face prevailing marital age preferences that often discriminate against them after they reach age 35 . This is likely due to women's declining fecundity over the life course (Wood 1994), since continuing the family bloodline is considered a crucial purpose of marriage in East Asia. In the case of Taiwan, the marriage life tables generated by the 2015 age-specific marriage rates (see Table 3 ) indicate that the probabilities of marrying at ages 30-34 among those individuals who were single at ages 25-29 were quite similar for men and women across educational groups, but also that the comparable probabilities of marrying at ages 35-39 were much higher for men than for women with tertiary education. These gender gaps in marriage further widen when people reach their early forties: at this point in the life course, about one-fifth of single men but fewer than $8 \%$ of single women with tertiary education can still expect to marry. With the expansion of tertiary education and the rising mean age at marriage in recent decades, this age prejudice can have considerable implications for future fertility levels in East Asia. First, shrinking cohort sizes and unbalanced sex ratios will create a substantial marriage squeeze to the disadvantage of men that will lead to fewer marriages and fewer childbirths, if non-marital births remain scarce. Second, with late motherhood stretching to above age 40 in many low-fertility societies (Beaujouan and Sobotka 2019), the low marriage rates among women beyond conventional marriageable ages in East Asia would make a potential fertility reversal much less likely in the future. 
Table 3:

Life table estimates of probability of marrying by age $X$ for women not married at age $Y$ across educational levels, Taiwan 2015

\begin{tabular}{ccccccc}
\hline & & \multicolumn{6}{c}{ Men } \\
\cline { 3 - 7 } Age $\boldsymbol{X}$ & Age $\boldsymbol{Y}$ & < High school & High school & Junior college & College+ & Total \\
\hline $30-34$ & $25-29$ & 0.2252 & 0.2985 & 0.4101 & 0.4321 & 0.3699 \\
$35-39$ & $30-34$ & 0.1530 & 0.2139 & 0.2905 & 0.3786 & 0.2734 \\
$40-44$ & $35-39$ & 0.0917 & 0.1214 & 0.1693 & 0.2215 & 0.1474 \\
& & \multicolumn{7}{c}{ Women } \\
\cline { 3 - 8 } Age $\boldsymbol{X}$ & Age $\boldsymbol{Y}$ & $<$ High school & High school & Junior college & College+ & Total \\
\hline $30-34$ & $25-29$ & 0.3747 & 0.3678 & 0.4472 & 0.4463 & 0.4266 \\
$35-39$ & $30-34$ & 0.2469 & 0.1996 & 0.2222 & 0.2437 & 0.2283 \\
$40-44$ & $35-39$ & 0.1435 & 0.0739 & 0.0752 & 0.0789 & 0.0829 \\
\hline
\end{tabular}

The prospects for fertility in East Asia can also be evaluated by using a recent forecast on levels of singlehood in East Asia. To gauge marriage patterns, Esteve et al. (2020) conducted a marriage forecast for four East Asian countries from 2010 up to 2050. They assumed that the prevailing marriage norms observed in 2010 will persist until 2050. The 2010 age- and educational-specific marriage propensities (Schoen 1988) were then applied to the projected population structure by age, sex, education and marital status up to 2050. The results indicated that lifelong singlehood among women aged 45-49 will likely reach 15\% in Korea and Japan and nearly 30\% in Taiwan; but a much lower level in China, which is expected to continue to have a universal marriage regime. Assuming that non-marital birth rates stay as low as they have been since 1970 in East Asia, married women will need to have about 2.1 children in Japan and 2.6 children in Taiwan for these countries to achieve a CTFR of 1.8 in 2050 - much less a level closer to replacement. Given that the marital fertility rate among the 1975 cohort in Taiwan is about 1.9 children (with a forecasted CTFR (1975) of 1.55, assuming 20\% of women never marry), a substantial increase in either the marriage or the marital fertility rates will be required for a demographically sustainable fertility level to occur.

Cultural and institutional factors are at the root of the sustained ultra-low fertility levels in East Asia. As significant demographic changes took place in the region within a short period of three to four decades, a clash of values has inevitably occurred between the older and the younger generations. To be more specific, low fertility in East Asia has been accompanied by declining marriage rates and minimal non-marital births largely because Confucian family norms continue to influence the socially acceptable timing and sequence of family behaviours. These rigid norms hamper the emergence of new values and behaviours among young adults, who are 
facing an increasingly diverse set of options and trajectories in life. For example, while prolonged education can substantially affect the timing of people's economic readiness for marriage, these societies show little tolerance for marriage in the absence of financial readiness, or for non-marital births. These norms have left the younger generations with few choices other than to postpone or forego marriage (and thus childbearing), which eventually results in societies having persistent low fertility and high levels of lifetime childlessness.

On the other hand, the collectivist culture that views child care as the responsibility of the family led to East Asian governments providing little support for families. However, these governments became more active in implementing pronatalist policies that promote work-family balance around the 1990s (for Japan) and 2000s. These new policies included the expansion of the provision of child care and parental leave policies (Suzuki 2012; Lee and Lin 2016). More policies were introduced after 2010, when the TFR remained stuck below 1.5 children. For instance, South Korea has invested more than 70 billion U.S. dollars in supporting childbearing since late 2000s (Poon 2018). But even though these Korean pronatalist policies provide some of the world's most generous child care subsidies and paid parental leave (52 weeks), the TFR in Korea declined to a record low of 0.92 in 2019. In response to a shortage of high quality public child care for children under age six, the Taiwanese government launched a "quasi-public child care" program in six major municipalities in August 2018 that converted private facilities into more affordable "quasi-public" child care (Focus Taiwan 2019). That is, the government recruited private preschools and kindergartens and provided subsidies in exchange for monitoring their fees and operations, thereby making them more affordable to parents. In 2019, this program was further expanded to all 22 administrative regions in Taiwan, and an income tax cut for families with dependent children was enacted (Focus Taiwan 2019). Finally, in 2018, the Japanese government announced that it will make preschool education free from ages three to five beginning in October 2019 (The Japan Times 2019). In mid-September 2019, Prime Minister Abe indicated that Japan plans to cover educational and medical expenses for all children under age 16 starting in October 2019.

It is too early to assess the impact and the effectiveness of these recent new policies on fertility and marriage. Given that the fertility levels of married women range from two children in Taiwan to fewer than two children in Hong Kong, Japan, Korea and China, declining marriage rates and marital fertility are key issues faced by these societies. Whether these recent policies will make childbearing more affordable and, thus, marriage more feasible for young adults remains to be seen. The differences between the TFR and the CTFR discussed earlier (see Table 1) suggest that Taiwan, Korea and China have slightly more leeway than Japan and Hong Kong, as the cohort completed fertility levels at age 40 for those born in 1970 are 1.7-1.75 children for the former group, yet only 1.43 and 1.15 for the latter two countries. The critical issues now are helping married couples have the number of children they want and supporting unmarried adults in forming families. While the former aim could be tackled by the recently enacted family policies, the latter 
goal will be hard to achieve before gender relations reach a more ideal state of equilibrium.

While replacement migration is a potential policy option for low-fertility countries, East Asian societies have not been particularly keen on pursuing this route. Migration policies in this region are often born out of expediency, and are seldom designed to increase diversity or to expand the young adult population. Even though the numbers of labour and marriage migrants to these countries have increased in recent decades, the labour migrants often face rigid governmental controls that prohibit them from settling (Piper 2004), while marriage migrants do not have more children than native-born women (Ishikawa 2015; Kim 2018; Yang et al. 2012). Thus, it appears that expanding immigration is not a policy choice that is likely to be adopted in low-fertility East Asia.

In short, in East Asia, population decline due to very low fertility levels is likely an inevitability. The causes of this phenomenon are not just insufficient policy support for families, but cultural and institutional factors that hamper family formation. While it takes time for more profound social transformation to happen, family forms have nonetheless diversified in East Asia as divorce rates have increased and cross-border marriages have become more prevalent in recent decades. With the legalisation of same-sex marriage in 2017 in Taiwan, it is possible to envision increasing family diversity in the years to come. The current ultra-low fertility observed in this region likely reflects a transitional state of social maladaptation to women's new roles and rapid family changes. In addition to policies that promote childbearing, governments in East Asia should think about how they can sustain or improve the well-being of their citizens in an ultra-low fertility context. While most existing research on the obstacles to fertility in East Asia studied the married population (Gauthier 2016), obstacles to marriage among the single population (Yoshida 2017) are perhaps equally important in this region. That is, if the demographic realities we are facing now reflect reluctant and involuntary outcomes among the younger generations, governments should perhaps seek to build a more flexible and supportive environment that promotes family formation. If, however, the current low levels of fertility and of marriage represent desirable life choices among the younger generations, then the problems of low fertility and population ageing should probably be tackled from angles other than through pronatalist policies, such as investing more in automation to counter the labour shortage and expanding migration to maintain a more sustainable tax base. After all, securing the welfare of the young and the old living in low-fertility contexts should always be the main policy priority.

\section{Acknowledgement}

The author would like to thank Mr. Chen-Hao Hsu for his excellent research assistance. 


\section{References}

Anderson, T. and H.-P. Kohler 2013. Education fever and the East Asian fertility puzzle: A case study of low fertility in South Korea. Asian Population Studies 9(2): 196-215. https://doi.org/10.1080/17441730.2013.797293

Attané, I. 2002. China's family planning policy: An overview of its past and future. Studies in Family Planning 33(1): 103-113. https://doi.org/10.1111/j.1728-4465.2002.00103.x

Barro, R. J. and J.-W. Lee 2018. Barro-Lee Educational Attainment Dataset. Retrieved from http://www.barrolee.com/.

Basten, S. 2015. Understanding ultra-low fertility in Hong Kong. In Low and lower fertility: Variations across developed countries, eds R. R. Rindfuss and M. K. Choe, 63-86. Cham: Springer International Publishing. https://doi.org/10.1007/978-3-319-21482-5_4

Basten, S. and G. Verropoulou 2013. 'Maternity migration' and the increased sex ratio at birth in Hong Kong SAR. Population Studies 67(3): 323-334. https://doi.org/10.1080/ 00324728.2013.826372

Beaujouan, É. and T. Sobotka 2019. Late childbearing continues to increase in developed countries. Population and Societies 562:1-4.

Brinton, M. C. and E. Mun 2016. Between state and family: managers' implementation and evaluation of parental leave policies in Japan. Socio-Economic Review 14(2): 257-281. https://doi.org/10.1093/ser/mwv021

Brinton, M. C. and E. Oh 2019. Babies, work, or both? Highly educated women's employment and fertility in East Asia. American Journal of Sociology 125(1): 105-140. https://doi.org/ $10.1086 / 704369$

Bumpass, L. L., R. R. Rindfuss, M. K. Choe and N. O. Tsuya 2009. The institutional context of low fertility. Asian Population Studies 5(3): 215-235. https://doi.org/10.1080/ 17441730903351479

Byoun, S. 2017. Non-marital cohabiters in Korea: Their experiences and values, research in brief. Sejong, South Korea: Korean Institute for Health and Social Affairs (KIHASA).

Cai, Y. 2010. China's below-replacement fertility: Government policy or socioeconomic development? Population and Development Review 36(3): 419-440. https://doi.org/10. 1111/j.1728-4457.2010.00341.x

Caldwell, J. C. and B. K. Caldwell 2005. Family size control by infanticide in the great agrarian societies of Asia. Journal of Comparative Family Studies 36(2): 205-226. https://doi.org/10.3138/jcfs.36.2.205

Census and Statistics Department 2018. Fertility trend in Hong Kong, 1981 to 2017. Hong Kong Monthly Digest of Statistics. Hong Kong, SAR: Demographic Statistics Section, Census and Statistics Department.

Chao, F., P. Gerland, A. R. Cook and L. Alkema 2019. Systematic assessment of the sex ratio at birth for all countries and estimation of national imbalances and regional reference levels. Proceedings of the National Academy of Sciences 116(19): 9303-9311. https://doi.org/10.1073/pnas.1812593116

Choi, E. J. and J. Hwang 2020. Transition of son preference: Evidence from South Korea. Demography 57(2): 627-652. https://doi.org/10.1007/s13524-020-00863-x 
Chuan, K. E. 2010. Will Singapore's fertility rise in the near future? A cohort analysis of fertility. Asian Population Studies 6(1): 69-82. https://doi.org/10.1080/17441731003603462

Den Boer, A. and V. Hudson 2017. Patrilineality, son preference, and sex selection in South Korea and Vietnam. Population and Development Review, 43(1): 119-147. https://doi.org/10.1111/padr.12041

Drixler, F. F. 2013. Mabiki: Infanticide and population growth in Eastern Japan, 1660-1950. Berkeley: University of California Press.

Esteve, A., J. García-Román, R. Kashyap, Y-.h. A. Cheng, F. Setsuya, W. Nie and H. O. Lee (2020). Demographic change and increasing late singlehood in East Asia, 2010-2050. Demographic Research 43: 1367-1398. https://doi.org/10.4054/DemRes.2020.43.46

Feeney, G. 1994. Fertility decline in East Asia. Science 266(5190): 1518-1523. https://doi. org/10.1126/science.7985021

Focus Taiwan 2019. Childcare subsidy coverage to be introduced nationwide in August. Focus Taiwan News Channel, accessed September 26. http://focustaiwan.tw/news/asoc/ 201904020023.aspx

Frejka, T. 2017. The fertility transition revisited: A cohort perspective. Comparative Population Studies 42: 89-116 https://doi.org/10.12765/CPoS-2017-09en

Frejka, T., G. W. Jones and J.-P. Sardon 2010. East Asian childbearing patterns and policy developments. Population and Development Review 36(3): 579-606. https://doi.org/10. 1111/j.1728-4457.2010.00347.x

Frejka, T. and J. Ross 2001. Paths to subreplacement fertility: The empirical evidence. Population and Development Review 27(Supplement: Global FertilityTransition): 213-254.

Fukuda, S., J. M. Raymo and S. Yoda 2020. Revisiting the educational gradient in marriage in Japan. Journal of Marriage and Family 82(4): 1378-1396. https://doi.org/10.1111/jomf. 12648.

Gauthier, A. H. 2016. Governmental support for families and obstacles to fertility in East Asia and other industrialized regions. In Low fertility, institutions, and their policies: Variations across industrialized countries, eds R. R. Rindfuss and M. K. Choe, 283-303. Cham: Springer International Publishing.

Gerber, A. 2015. Ko says unmarried men, women equally a danger to security (http://www. taipeitimes.com/News/taiwan/archives/2015/02/17/2003611766). Taipei Times, Feb. 17.

Gietel-Basten, S. 2018. Fertiltiy Decline. In Routledge handbook of Asian demography, eds Zhongwei Zhao and Adrian C. Hayes, 64-86. New York, NY: Routledge.

Gietel-Basten, S. 2019. The "population problem" in Pacific Asia. New York, NY: Oxford University Press.

Gietel-Basten, S., X. Han and Y. Cheng 2019. Assessing the impact of the "onechild policy" in China: A synthetic control approach. PLOS ONE 14(11): e0220170. https://doi.org/10.1371/journal.pone.0220170

Gietel-Basten, S. and G. Verropoulou 2018. The changing relationship between marriage and childbearing in Hong Kong. PLOS ONE 13(3): e0194948. https://doi.org/10.1371/ journal.pone.0194948

Gjerdingen, D. K. and B. A. Center 2005. First-time parents' postpartum changes in employment, childcare, and housework responsibilities. Social Science Research 34(1): 103-116. https://doi.org/10.1016/j.ssresearch.2003.11.005 
Goodkind, D. 2011. Child underreporting, fertility, and sex ratio imbalance in China. Demography 48(1): 291-316. https:/doi.org/10.1007/s13524-010-0007-y

Goodkind, D. 2017. The astonishing population averted by China's birth restrictions: Estimate, nightmares, and reprogrammed ambitions. Demography 54: 1375-1400. https://doi.org/10.1007/s13524-017-0595-X

Guilmoto, C. Z. 2015. The masculinization of births. Overview and current knowledge. Population 70(2): 185-243.

Guo, Z., S. Gietel-Basten and B. Gu 2019. The lowest fertility rates in the world? Evidence from the 2015 Chinese $1 \%$ sample census. China Population and Development Studies 2(3): 245-258. https://doi.org/10.1007/s42379-018-0012-1

Hsia, H.-C. 2007. Imaged and imagined threat to the nation: The media construction of the 'foreign brides' phenomenon'as social problems in Taiwan. Inter-Asia Cultural Studies 8(1): 55-85. https://doi.org/10.1080/14649370601119006

Hsiao, Y.-L. 2005. The division of household labor in Taiwan: Economic dependence and gender. Taiwanese Journal of Sociology 34: 115-45. https://doi.org/10.6786/TJS

Hsu, P. 2008. Gender inequality and the division of household labor: Comparisons among China, Japan, South Korea, and Taiwan. Ph.D. Dissertation, Cornell University.

International Labor Organization 2019. Summary Tables, ILOSTAT. Genève, Switzerland: Department of Statistics, International Labor Organization.

Ishikawa, Y. 2015. International migrants in Japan: Contributions in an era of population decline: Government Printing Office.

Iwasawa, M. and K. Kamata 2014. Marriage preceded by pregnancy and women's employment. Japan Labor Review 11(4): 21-51.

Jackson, S., J. Liu and J. Woo 2008. Reflections on gender, modernity and East Asian sexualities. In East Asian sexualities: Modernity, gender $\mathcal{F}$ new sexual cultures, eds J. Liu, S. Jackson and J. Woo. London, UK: Zed Books.

Ji, Y. and W. -J. J. Yeung 2014. Heterogeneity in contemporary Chinese marriage. Journal of Family Issues 35(12): 1662-1682. https://doi.org/10.1177/0192513X14538030

Jones, G. W. 2019. Ultra-low fertility in East Asia: policy responses and challenges. Asian Population Studies 15(2): 131-149. https://doi.org/10.1080/17441730.2019.1594656

Jones, G. W. 2007. Delayed marriage and very low fertility in Pacific Asia. Population and Development Review 33(3): 453-478. https://doi.org/10.1111/j.1728-4457.2007.00180.x

Jones, G. W. 2013. The growth of the one-child family and other changes in the low fertility countries of Asia. In Fertility rates and population decline: No time for children?, eds A. Buchanan and A. Rotkirch, 44-61. London: Palgrave Macmillan UK.

Kim, E. H.-W. 2017. Division of domestic labour and lowest-low fertility in South Korea. Demographic Research 37: 743-768. https://doi.org/10.4054/DemRes.2017.37.24

Kim, E. H.-W. and A. K.-L. Cheung 2019. The gendered division of household labor over parenthood transitions: A longitudinal study in South Korea. Population Research and Policy Review 38(4): 459-482. https://doi.org/10.1007/s11113-018-09508-9

Kim, H. S. 2018. Fertility differentials between Korean and international marriage couples in South Korea. Asian Population Studies 14(1): 43-60. https://doi.org/10.1080/17441730. 2018.1426188 
Kim, Y. and J. Lee 2018. Bridal pregnancy and women's educational attainment in South Korea, 1970-2009. The History of the Family 23(3): 426-445. https://doi.org/10.1080/ 1081602X.2018.1474785

Lee, M. and Y.-H. Lin 2016. Transition from anti-natalist to pro-natalist policies in Taiwan. In Low Fertility, Institutions, and their Policies, 259-281. Springer. https://doi.org/10. 1007/978-3-319-32997-0_10

Lee, S. 2009. Low fertility and policy responses in Korea. The Japanese Journal of Population 7(1): 57-70.

Lee, S. and H. Choi 2015. Lowest-low fertility and policy responses in South Korea. In Low and lower fertility: Variations across developed countries, eds R. R. Rindfuss and M. K. Choe, 107-123. Switzerland: Springer. https://doi.org/10.1007/978-3-319-21482-5_6

Lee, S.-E. 2016. International marriages can lead to heartache. Korea JoongAng Daily. http://koreajoongangdaily.joins.com/news/article/article.aspx?aid=3026133

Leng, S. 2017. An inconvenient truth? China omits key figures that may have highlighted its demographic time bomb from official statistics. South China Morning Post, October 27, 2017. Accessed July 26, 2018. https://www.scmp.com/news/china/economy/article/ 2117167/inconvenient-truth-china-omits-keyfigures-may-have-highlighted

Lesthaeghe, R. J. 2010. The unfolding story of the second demographic transition. Population and Development Review 36(2): 211-251. https://doi.org/10.1111/j.1728-4457.2010. 00328.x

Marginson, S. 2011. Higher education in East Asia and Singapore: Rise of the Confucian model. Higher Education 61(5): 587-611. https://doi.org/10.1007/s10734-010-9384-9

McCurry, J. 2019. Politician scolds female professor for not having child. The Guardian, September 5, 2019. https://www.theguardian.com/world/2019/sep/05/south-koreanpolitician-scolds-female-professor-for-not-having-child

McDonald, P. 2009. Explanations of low fertility in East Asia: A comparative perspective. In Ultra-low fertility in Pacific Asia: Trends, causes, and policy issues, 23-39. New York, NY: Routledge.

Ministry of Employment and Labor 2019. Employment insurance database, Republic of Korea. Sejong, Republic of Korea: Ministry of Employment and Labor. Retrieved from http://www.index.go.kr/potal/stts/idxMain/selectPoSttsIdxSearch.do?idx_cd=1504\& clas_div=\&idx_sys_cd=528\&idx_clas_cd=1, accessed on 18 September 2019.

Ministry of Labor 2019. Labor statistics database, Taiwan. Taipei, Taiwan: Ministry of Labor. Retrieved from https://www.mol.gov.tw/statistics/2461/19518/, accessed on 18 September 2019.

Mun, E. 2015. Negative compliance as an organizational response to legal pressures: The case of Japanese equal employment opportunity law. Social Forces 94(4): 1409-1437. https://doi.org/10.1093/sf/sov118

Mun, E. and M. C. Brinton 2015. Workplace matters: The use of parental leave policy in Japan. Work and Occupations 42(3): 335-369. https://doi.org/10.1177/0730888415574781

Myrskylä, M., J. R. Goldstein and Y. A. Cheng 2013. New cohort fertility forecasts for the developed world: Rises, falls, and reversals. Population and Development Review 39(1): 31-56. https://doi.org/10.1111/j.1728-4457.2013.00572.x 
OECD 2019. OECD Family Database. Paris, France: Organization for Economic Cooperation and Development. Retrieved from http://www.oecd.org/els/family/database.htm, accessed on 18 September 2019.

OECD Korea Policy Centre 2018. Family Database in the Asia-Pacific Region. Retrieved from http://www.oecdkorea.org/user/nd8662.do?View\&boardNo=00002453, accessed on 18 September 2019.

Ogawa, N., A. Mason, S.-H. Lee, A.-C. Tung and R. Matsukura 2015. Very low fertility and the high costs of children and the elderly in East Asia. In Low fertility and reproductive health in East Asia, eds N. Ogawa and I. H. Shah, 31-58. Dordrecht, Netherlands: Springer. https://doi.org/10.1007/978-94-017-9226-4_3

Ogawa, N. and I. H. Shah 2015. Low fertility and reproductive health in East Asia. Vol. 11. New York, NY: Springer. https://doi.org/10.1007/978-94-017-9226-4

Peng, X. 1991. Demographic transition in China: Fertility trends since the 1950s. Oxford: Clarendon Press.

Piper, N. 2004. Rights of foreign workers and the politics of migration in South-East and East Asia. International Migration 42(5): 71-97. https://doi.org/10.1111/j.0020-7985. 2004.00302.x

Poon, L. 2018. South Korea is trying to boost its birth rate. It's not working. The Atlantic Monthly Group, accessed September 26. https://www.citylab.com/life/2018/08/southkorea-needs-more-babies/565169/

Poston, D. L. 2000. Social and economic development and the fertility transitions in mainland China and Taiwan. Population and Development Review supplement to vol. 26: 40-60.

Qin, A. 2019. A prosperous China says 'men preferred,' and women lose. The New York Times, July 16, 2019. Accessed August 6, 2019. https://www.nytimes.com/2019/07/16/ world/asia/china-women-discrimination.html

Raymo, J. M., M. Iwasawa and L. Bumpass 2009. Cohabitation and family formation in Japan. Demography 46(4): 785-803. https://doi.org/10.1353/dem.0.0075

Raymo, J. M., H. Park, Y. Xie and W. Jean Yeung 2015. Marriage and family in East Asia: Continuity and change. Annual Review of Sociology 41(1): 471-492. https://doi.org/10. 1146/annurev-soc-073014-112428

Sano, Y. and S. Yasumoto 2014. Policy responses to population-declining society: Development and challenges of family policies in Japan. In Handbook of Family policies across the globe, ed M. Robila, 319-331. New York, NY: Springer New York. https://doi.org/10.1007/978-1-4614-6771-7_21

Schoen, R. 1988. Modeling multigroup populations. New York, NY: Plenum.

Steger, I. 2018. Almost no men used to take South Korea's generous paternity leave. That's changing. Quartz Media, Inc., Last Modified July 25, 2018. https://qz.com/1335909/ number-of-south-korean-men-taking-paternity-leave-jumps-66-in-2018/

Straughan, P., A. Chan and G. Jones 2008. Ultra-low fertility in Pacific Asia: Trends, causes and policy issues. London, UK: Routledge.

Suzuki, T. 2012. Low fertility and governmental intervention in Japan and Korea. The Japanese Journal of Population 10(1): 60-77.

The Family Planning Association of Hong Kong 2017. Report on youth sexuality study, 2016. Hong Kong, SAR: The Family Planning Association of Hong Kong. 
The Global Economy 2019. The Global Economy Database. Retrieved from https://www. theglobaleconomy.com/indicators_list.php, accessed on 18 September 2019.

The Guttmacher Institute 2019. Abortion in Asia. The Guttmacher Institute, accessed September 18. https://www.guttmacher.org/fact-sheet/abortion-asia

The Japan Times 2019. Japan enacts legislation making preschool education free in effort to boost low fertility rate. The Japan Times. https://www.japantimes.co.jp/news/2019/05/10/ national/japan-enacts-legislation-making-preschool-education-free-effort-boost-lowfertility-rate/\#.XYiZ1mZ-WU1

The Ministry of Health Labor and Welfare 2019. Basic survey of gender equality in employment management, Japan. The Ministry of Health, Labor and Welfare. https://www.mhlw.go.jp/toukei/list/71-23c.html

The National Institute of Population and Social Security Research 2018. Population statistics of Japan, 2017. Tokyo, Japan: The National Institute of Population and Social Security Research.

Tsuya, N. O. 2006. Patterns and covariates of partnership formation in Japan. Jinko Mondai Kenkyu/Journal of Population Problems 62(1-2): 1-19.

Tsuya, N. O. 2017. Low fertility in Japan-No end in sight. AsiaPacific Issues 131: 1-4.

Tung, A.-C. 2011. Are children consuming more overtime? An application of the national transfer accounts method (in Chinese). Taiwan Economic Forecast and Policy 42 (1): $119-148$.

United Nations 2014. World Fertility Report 2013: Fertility at the extremes. New York, NY: Department of Economic and Social Affairs, United Nations.

Weber, M. 1958. The Chinese Literati (originally published in German in 1915). In From Max Weber: Essays in sociology, eds Hans H. Gerth and C. Wright Mills. New York, NY: Oxford University Press.

Wood, J. W. 1994. Dynamics of human reproduction: Biology, biometry and demography. New York, NY: Aldine de Gruyter.

Yang, C., I. Huang, H.-J. Tsai and H. Wang 2012. Comparisons of fertility rate and birth quality between native and foreign-born women in Taiwan (in Chinese). Journal of Social Sciences and Philosophy 24(1): 83-120.

Yang, J. 2017. Gendered division of domestic work and willingness to have more children in China. Demographic Research 37: 1949-1974. https://doi.org/10.4054/DemRes.2017.37. 62

Yeung, W.-J. Jean, S. Desai and G. W Jones 2018. Families in Southeast and South Asia. Annual Review of Sociology 44: 469-495. https://doi.org/10.1146/annurev-soc-073117041124

Yoo, H. 2015. Living cohabitation in the Republic of Korea: The reported experiences of lesbians, gays and heterosexuals. Ph.D. dissertation. Centre for Women's Studies, University of York.

Yoo, S. H. and T. Sobotka 2018. Ultra-low fertility in South Korea: The role of the tempo effect. Demographic Research 38: 549-576. https://doi.org/10.4054/DemRes.2018.38.22

Yoshida, A. 2017. Unmarried Women in Japan: The drift into singlehood. New York, NY: Routledge. https://doi.org/10.1093/ssjj/jyx042

Yu, J. and Y. Xie 2015. Cohabitation in China: Trends and determinants. Population and Development Review 41(4): 607-628. https://doi.org/10.1111/j.1728-4457.2015.00087.x 
Open Access This article is published under the terms of the Creative Commons Attribution 4.0 International License (https://creativecommons.org/licenses/by/4.0/) that allows the sharing, use and adaptation in any medium, provided that the user gives appropriate credit, provides a link to the license, and indicates if changes were made. 